\title{
Berberine for the treatment of hypertension: a systematic review
}

\author{
lain Atherton
}

Marco Tullio Suadoni 


\section{Abstract}

\section{Background}

Hypertension is the highest risk factor for disease globally. When prescription of drug therapy is recommended, patients might decline treatment due to hypertension asymptomatic nature, sometimes turning to alternative therapies. One popular therapy is berberine, a plant alkaloid that has been used in eastern medicine for millennia to treat several ailments, including cardiovascular diseases and their risk factors.

\section{Aims}

Through a transparent and pragmatic approach towards searching, synthesising, assessing, and reporting the available clinical evidence, the present review aimed to investigate berberine effect on blood pressure and cardiovascular disease risk. It also intended to provide guidance for clinician when advising their patients, and to highlight gaps in the research along offering suggestions to fill them.

\section{Methods}

The review was conducted following the protocol PRISMA-P, and reported according to the related PRISMA statement. The PICO framework was used to define the scope of the review, and to arrive at a database search strategy. The strategy was run on the databases Medline, CINAHL, AMED, Embase, and Cochrane Library through the platforms EBSCOhost and Ovid. Citations were exported to Mendeley citation manger for screening. Relevant studies were selected based on specified inclusion and exclusion criteria. Data from included studies was extracted in the form of a detailed table of characteristics of studies, and summarised in an evidence table. Quality of studies was assessed using the SIGN methodology checklist for controlled trials. The results from the quality assessment were summarised through an adaptation of the Robvis tool software package output. Effect estimates and their precision were calculated with RevMan 5 computer program from the extracted study outcomes.

\section{Results}

Five randomised controlled trials and two non-randomised controlled trials were included with 614 participants. All provided data on blood pressure, but none measured cardiovascular events or longterm adverse events. The group of studies was highly heterogeneous in terms of experimental 
intervention, comparator intervention, length to follow-up, participants' diagnosis, and setting. The heterogeneity prevented a meaningful meta-analysis. Berberine plus amlodipine was not significantly better than amlodipine alone at reducing systolic and diastolic blood pressure. Compared to metformin, berberine provided a statistically significant moderate reduction effect on systolic blood pressure $(-11.87$ [-16.64, -7.10] mmHg). A proprietary nutraceutical containing berberine as one of its ingredients was in one study significantly effective at reducing blood pressure compared to placebo $(-11.80$ [-18.73, -4.87] mmHg systolic, and -11.10 [-15.17, -7.43] mmHg diastolic), and also effective in another study compared to dietary advice (-3.40 [-5.48, -1.32] mmHg for systolic 24h ambulatory blood pressure), although effects could not be reliably attributed to berberine alone. The herbal extract Chunghyul-dan, which contains berberine, showed a significant beneficial moderate effect compared to no treatment on systolic 24h ambulatory blood pressure $(-7.34$ [-13.14, -1.54] mmHg) in one study, but in another study employing higher dose and longer treatment duration, no effects were detected. Again, the effects could not be attributed to berberine alone. The quality of the body of evidence was low, especially due to lack of trial design details and presence of outcome reporting bias.

\section{Conclusions}

The evidence around berberine effect on blood pressure is limited, of low quality, and ultimately inconclusive. Clinicians should be aware that the evidence from randomised trials is not sufficient to establish berberine effectiveness and safety in the treatment of hypertension, and they should balance these findings with the long history of berberine use in the Eastern world. Researchers should aim at improving quality of studies, by raising the standard of designing and reporting them, e.g., by following the CONSORT guidelines, and strive to measure meaningful clinical endpoints, such as cardiovascular events, mortality, and adverse outcomes. 


\section{Table of contents}

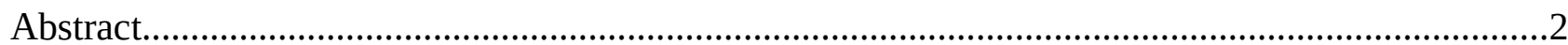

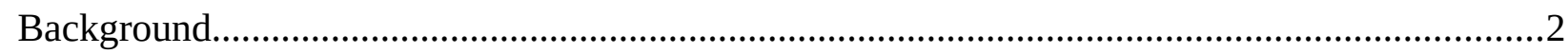

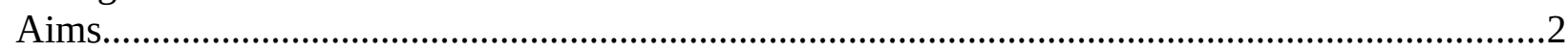

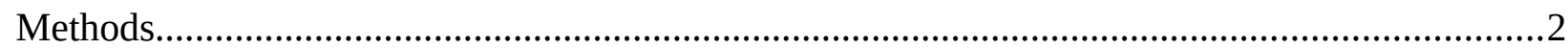

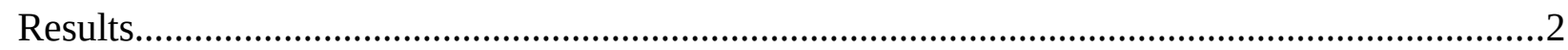

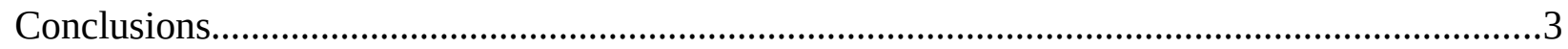

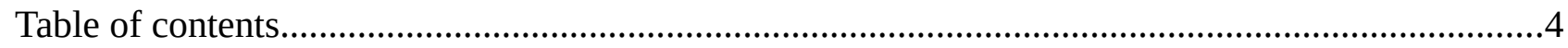

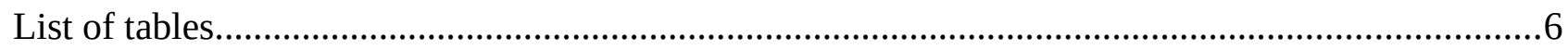

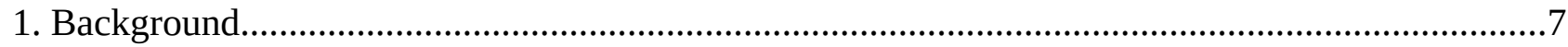

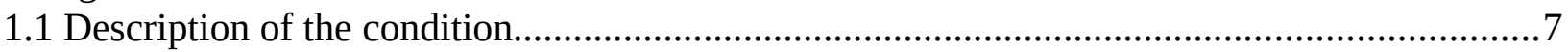

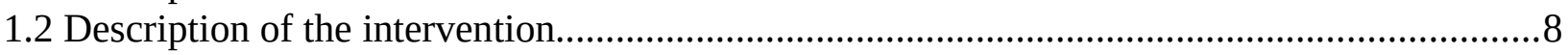

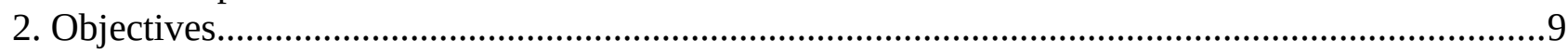

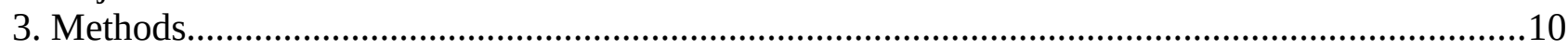

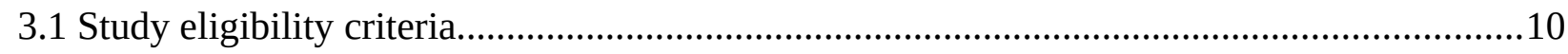

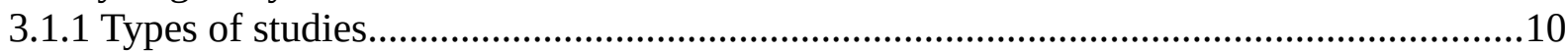

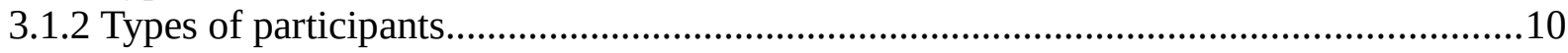

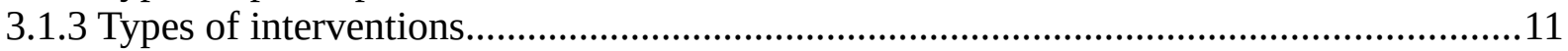

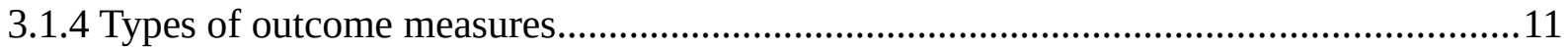

3.2 Search methods for identification of studies...................................................................12

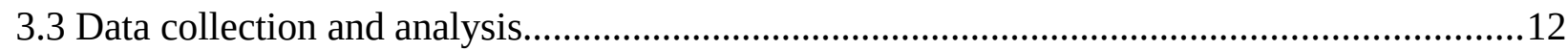

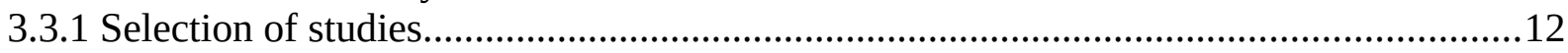

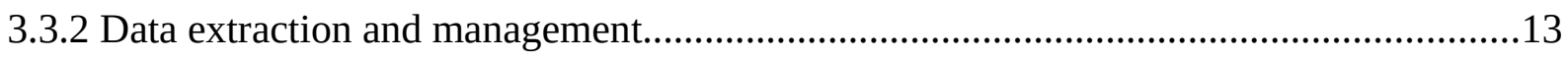

3.3.3 Assessment of risk of bias in the included studies...................................................... 13

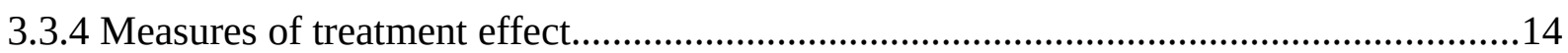

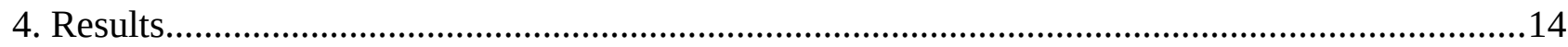

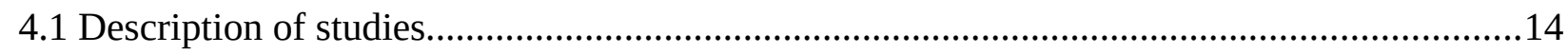

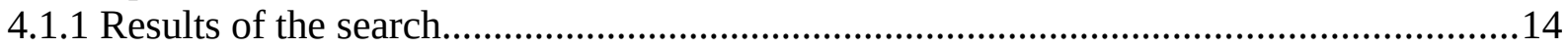

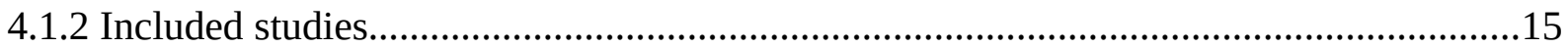

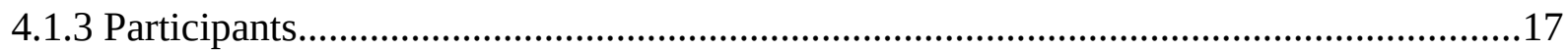

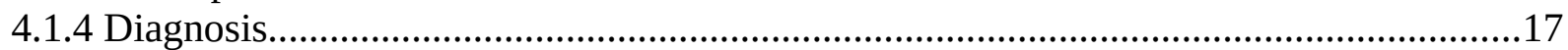

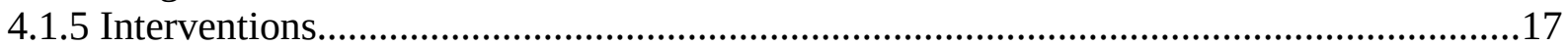

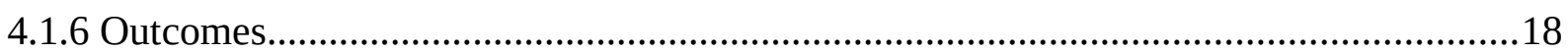

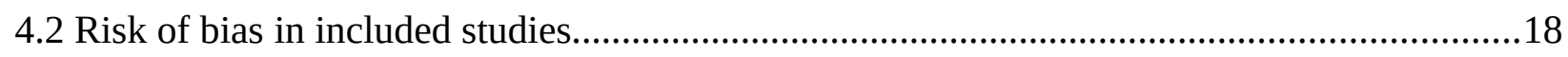

4.2.1 Overview of risk of bias in included studies............................................................18

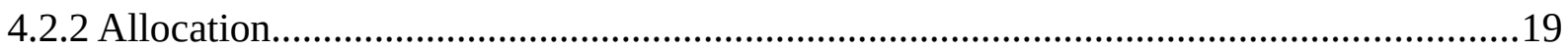

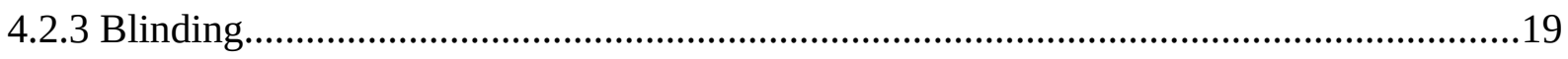

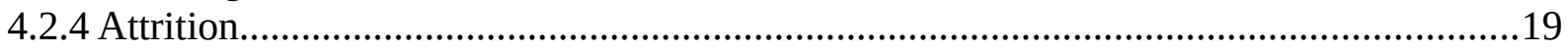

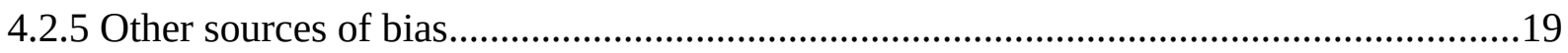

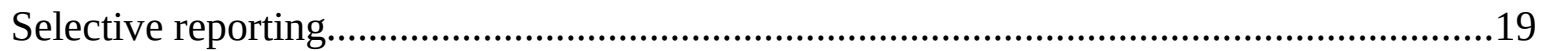

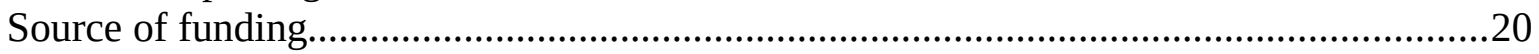

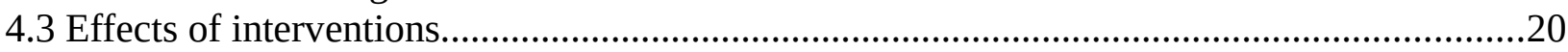

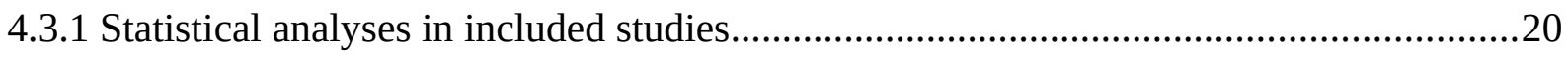




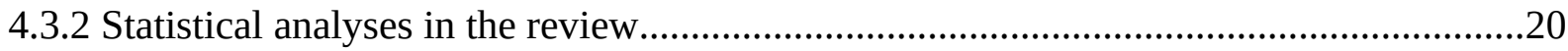

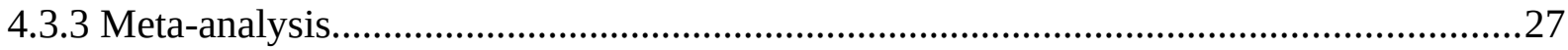

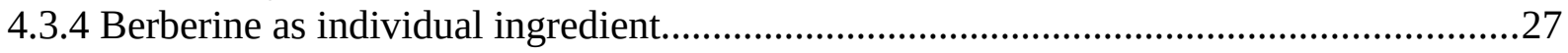

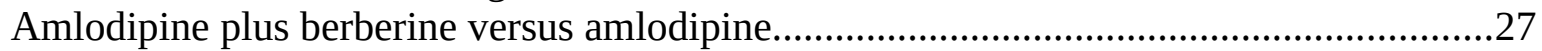

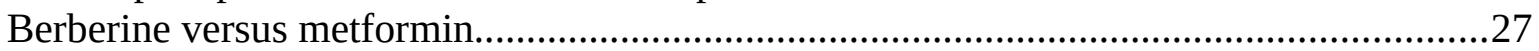

4.3.5 Proprietary preparations containing berberine........................................................28

Armolipid Plus plus dietary prescription versus dietary prescription only.......................28

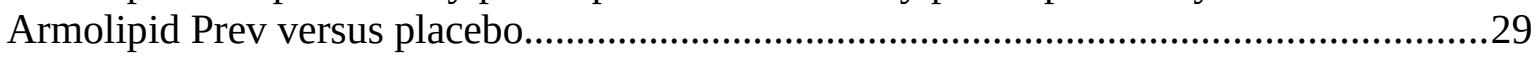

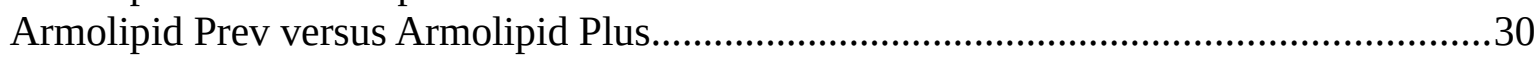

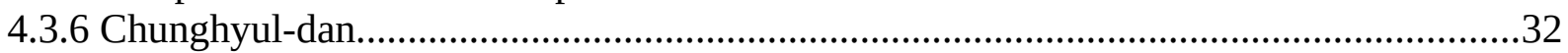

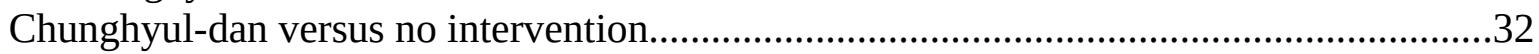

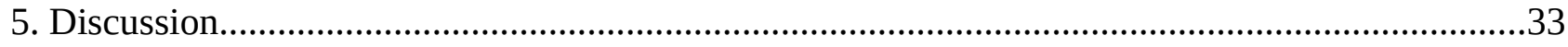

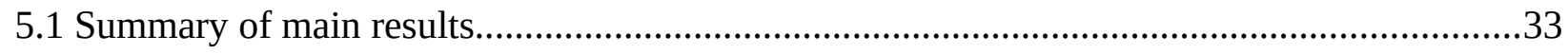

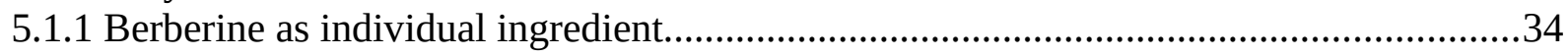

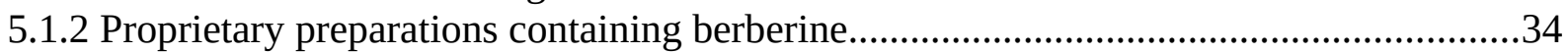

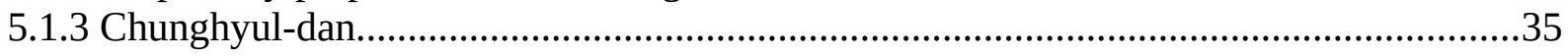

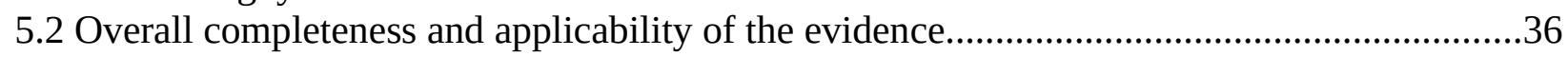

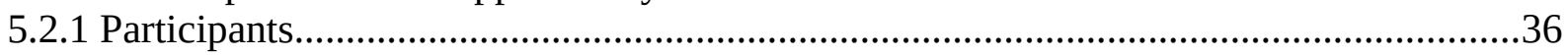

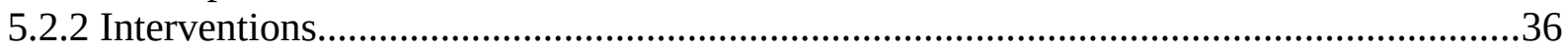

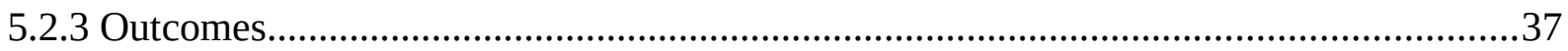

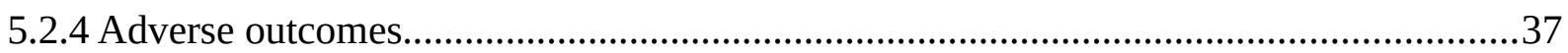

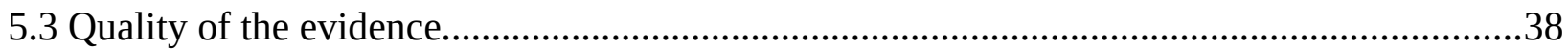

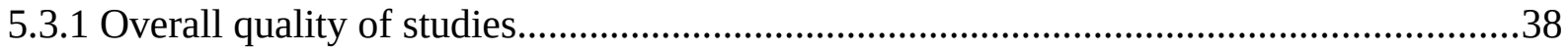

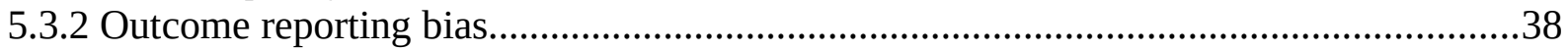

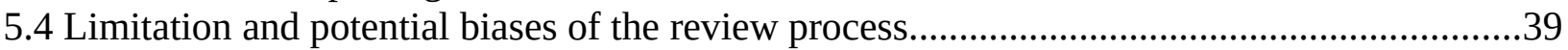

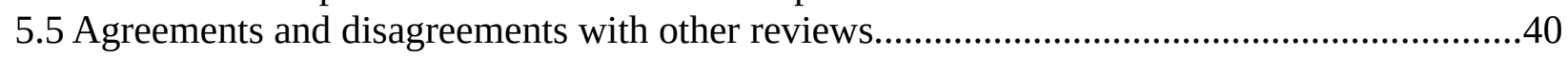

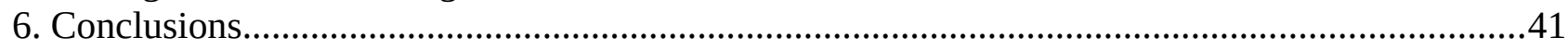

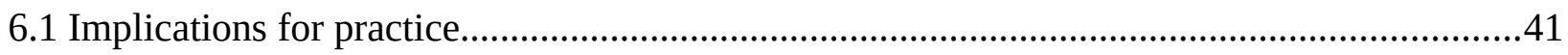

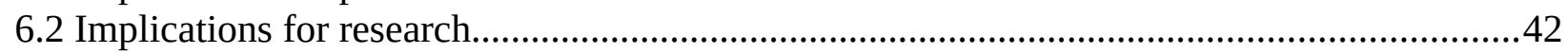

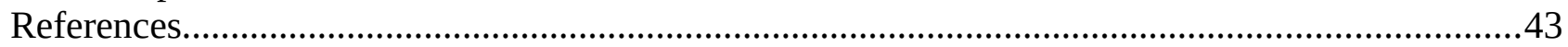

Appendix 1 - Characteristics of included studies.................................................................49

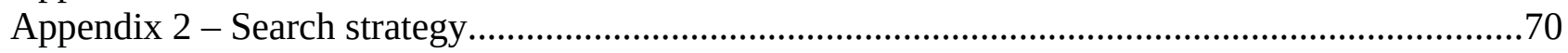

Boolean phrase for Medline, CINAHL, and AMED in EBSCOHost.....................................70

Boolean phrase for Embase in Ovid.........................................................................................

\section{List of figures}

Figure 1. PRISMA flow diagram of study selection process: berberine for the treatment of

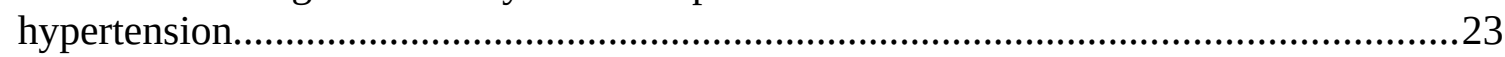

Figure 2. "Traffic light” plot of the question-level judgments for each study...............................28

Figure 3. Bar plot of the distribution of judgments within each question.......................................29

Figure 4. Forest plot comparison: amlodipine plus berberine versus amlodipine; outcome: SBP at

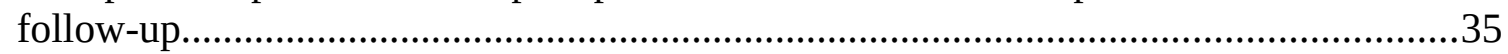

Figure 5. Forest plot comparison: amlodipine plus berberine versus amlodipine; outcome: DBP at

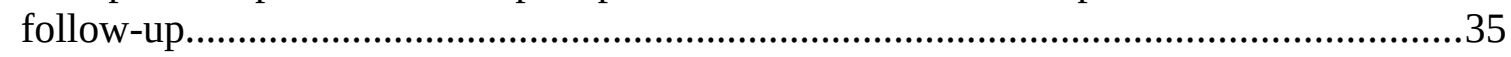

Figure 6. Forest plot comparison: berberine versus metformin; outcome: SBP at follow-up............36

Figure 7. Forest plot comparison: berberine versus metformin; outcome: DBP at follow-up...........36 
Figure 8. Forest plot comparison: Armolipid Plus plus diet versus diet; outcome: systolic

24h-ABPM at follow-up......................................................................................... 24h-ABPM at follow-up.

Figure 10. Forest plot comparison: Armolipid Prev versus placebo; outcome: SBP at follow-up.....38

Figure 11. Forest plot comparison: Armolipid Prev versus placebo; outcome: DBP at follow-up....38

Figure 12. Forest plot comparison: Armolipid Prev versus placebo; outcome: SBP change from 2-week run-in to follow-up.

Figure 13. Forest plot comparison: Armolipid Prev versus placebo; outcome: DBP change from 2-week run-in to follow-up.

Figure 14. Forest plot comparison: Armolipid Prev versus Armolipid Plus; outcome: 24h ambulatory SBP at follow-up.

Figure 15. Forest plot comparison: Armolipid Prev versus Armolipid Plus; outcome: 24h ambulatory DBP at follow-up.

Figure 16. Forest plot comparison: Armolipid Prev versus Armolipid Plus; outcome: daytime ambulatory SBP at follow-up.....

Figure 17. Forest plot comparison: Armolipid Prev versus Armolipid Plus; outcome: daytime ambulatory DBP at follow-up.....

Figure 18. Forest plot comparison: Armolipid Prev versus Armolipid Plus; outcome: night-time ambulatory SBP at follow-up.

Figure 19. Forest plot comparison: Armolipid Prev versus Armolipid Plus; outcome: night-time ambulatory DBP at follow-up.

Figure 20. Forest plot comparison: Chunghyul-dan versus no intervention; outcome: 24h ambulatory SBP at follow-up.

Figure 21. Forest plot comparison: Chunghyul-dan versus no intervention; outcome: 24h ambulatory DBP at follow-up.

Figure 22. Forest plot comparison: Chunghyul-dan versus no intervention; outcome: 24h ambulatory SBP change from baseline to follow-up.

\section{List of Tables}

Table 1. Summary of features of included studies answering the review question: does treatment with berberine reduce blood pressure and cardiovascular events in adults with primary hypertension?.

Table 2. Outcome reporting bias analysis. 


\section{Background}

\subsection{Description of the condition}

High blood pressure, commonly known as hypertension, has long been accepted as a major risk factor for stroke, cardiovascular disease, renal disease, and overall mortality [1]. Blood pressure is a biological continuous variable with a normal distribution across the general population. Hypertension is diagnosed when blood pressure is above an arbitrarily set threshold at the high end of the distribution. The threshold for hypertension is set pragmatically at a level above which the related risk of cardiovascular disease warrants treatment and investigations that would do more good than harm [2].

The National Institute for Health and Care Excellence (NICE) defines hypertension as a blood pressure of 140/90 mmHg (systolic/diastolic) or higher when measured in clinic and either a subsequent daytime ambulatory blood pressure monitoring (ABPM) average or home blood pressure monitoring average of $135 / 85 \mathrm{mmHg}$ or higher [3]. A clinic blood pressure reading between 120/80 mmHg and 140/90 mmHg is defined as high-normal blood pressure [4].

Hypertension is categorised as primary and secondary hypertension. The latter generally appears earlier in life, independently of family history, has an established cause, such as a renal or endocrine condition, or can be iatrogenic, as in the use of oral contraceptive use [2]. Secondary hypertension should always be suspected in adults under 40 who have hypertension, and should trigger further investigations to establish a possible secondary cause [3]. If the cause can be eliminated, secondary hypertension could resolve without further interventions. In contrast, primary hypertension, also known as essential hypertension, occurs mostly later in life, due to a combination of lifestyle and hereditary factors. In the reminder of this review, the terms hypertension, primary hypertension, and essential hypertension will be used interchangeably.

In the Global Burden of Disease (GBD) 2015 [5], hypertension represented the highest burden among risk factors for disease globally, affecting one in four adults. The GBD also showed that in the UK, hypertension was the third biggest risk factor for disease after tobacco smoking and obesity. At the same time, high blood pressure is the largest single known risk factor for cardiovascular disease and associated disability. The GBD estimated that in 2015 in England there 
were 12.5 million people, one in four, affected by hypertension. The latter was responsible for 75,000 deaths in that year.

Current evidence shows that lowering blood pressure reduces the above risks. For example, in an extensive meta-analysis on blood pressure lowering treatment published in the Lancet, Ettehad et al. [5] pooled data from 123 trials dating from 1966 to 2015 which included 613,815 participants. They found that every $10 \mathrm{mmHg}$ reduction in systolic blood pressure resulted in $28 \%$ reduction for the risk of heart failure, $27 \%$ reduction for stroke, $17 \%$ reduction for coronary heart disease, and 13\% reduction for all-cause mortality.

Steps have been made towards reducing the English population's blood pressure level. The Health Survey for England 2018 [6] demonstrates that over the last ten years the population's systolic blood pressure has decreased by almost $3 \mathrm{mmHg}$ on average. However, not much progress has been made over the last three years.

\subsection{Description of the intervention}

When lifestyle and dietary changes do not sufficiently lower a patient's blood pressure to at least the high-normal range, a drug treatment is offered. Generally, patients are less enthusiastic than clinicians about starting an antihypertensive drug regimen, a trend common to therapies that are preventative of a disease rather than intended to treat it. In the UK, as much as 50\% of patients at moderate risk of cardiovascular disease have been estimated as likely to decline antihypertensive drugs [7]. When patients decline their doctor's or practice nurse's treatment, they might seek alternative approaches. In their systematic review of Europe citizen's attitude in relation to alternative medicine, Nissen et al. [8] found that the studies they included reported between 54\% and $66 \%$ of UK healthcare users as supporting the provision of alternative therapies in the National Health Service. Also, they highlighted that citizens wish for more support and knowledge from healthcare professionals about alternative therapies.

Across Europe, herbal medicine is one of the most popular alternative therapies that patients use [9]. Among them is berberine, a yellow coloured isoquinolone alkaloid herbal derivative which has received much attention in its application for the treatment of various conditions, including type 2 diabetes mellitus, hypercholesterolaemia, and hypertension. Plants containing berberine have been used in Chinese and Ayurvedic medicine for over 2500 years for their antimicrobial, antiprotozoal, 
and antidiarrheal activity [10]. Berberine is found in varying proportions in roots, rhizomes, stems, and bark of several species of the Ranuncolaceae family, including Berberis vulgaris (barberry), Berberis aristata (tree turmeric), Copti chinensi (Chinese goldthread), Coptis trifolia (American goldthread), and Hydrastis canadensis (goldenseal) [11]. Several studies have investigated berberine effects on cardiovascular disease, making berberine one of the most widely studied herbal constituent of the last decades [12]. In recent years, researchers have pooled the growing body of evidence into several narrative reviews of the effects of berberine on various illnesses, including diabetes, dyslipidaemia, dementia, cancer, and hypertension [13-17]. The search carried out for the present review revealed only one systematic review on berberine for the treatment of hypertension [18]. It is somewhat dated and its meta-analysis has some errors which put into question its conclusion on berberine effect on blood pressure. Further insights are given in the Discussion section under Agreements and disagreements with other reviews. It seemed therefore appropriate to conduct a systematic review to clarify the role of berberine in the treatment of hypertension.

\section{Objectives}

This systematic review aims at evaluating the effectiveness of berberine in reducing blood pressure and cardiovascular events. The 'Population, Intervention, Comparison(s) and Outcome' (PICO) framework, first proposed by Richardson et al. [19], was used to arrive at a review question for which all components would be well defined. The Cochrane Handbook suggests that equal emphasis in defining each PICO component is not necessary [20]. In this review the comparison element was left out to increase sensitivity. The following PICO question was then formulated:

Does treatment with berberine reduce blood pressure and cardiovascular events in adults with primary hypertension?

From this starting point, the review ultimate aim is to distill for clinicians, and especially primary care doctors and practice nurses who are at the front line of prevention of cardiovascular disease, the evidence available around berberine when used for treatment of hypertension. In particular, the focus is on establishing the quality of evidence around berberine efficacy and safety in lowering blood pressure and in providing long-term benefits through the reduction of cardiovascular events in patients with hypertension. It is hoped that clinicians, should they encounter patients using berberine, will then be better equipped to give advice and support to these patients, and provide treatment that is safe and effective. 


\section{Methods}

The Preferred Reporting Items for Systematic Reviews and Meta-Analyses (PRISMA) statement [21] defines a systematic review as an essential tool to collate evidence comprehensively, accurately, and clearly, to then synthesise and draw conclusions from the whole range of available data. The drafting of this report has followed the PRISMA statement. The PRISMA protocol (PRISMA-P) [22] was fallowed to carry out the review.

\subsection{Study eligibility criteria}

\subsubsection{Types of studies}

Studies were included if they were designed as controlled trials, regardless of randomization, blinding, publication status, or language. Observational studies and studies designed as before-after studies, interrupted time-series, and cross sectional studies were excluded. Regardless of the identification of the type of study design given in the related paper, the type of study design was determined through the NICE algorithm for classifying quantitative study designs [23].

\subsubsection{Types of participants}

Participants had to be human adults aged 18 and above who had primary hypertension. Studies were included if study participants had a mean baseline blood pressure satisfying at least one of the NICE criteria for the diagnosis of hypertension [3]. Therefore, studies were included if the baseline mean blood pressure values of participants in both experimental group and comparator group satisfied at least one of the following criteria:

- Clinic systolic blood pressure (SBP) higher than or equal to $140 \mathrm{mmHg}$

- Clinic diastolic blood pressure (DBP) higher than or equal to $90 \mathrm{mmHg}$

- Daytime systolic ABPM higher than or equal to $135 \mathrm{mmHg}$

- $\quad$ Daytime diastolic ABPM higher than or equal to $85 \mathrm{mmHg}$

- Home systolic blood pressure monitoring higher than or equal to $135 \mathrm{mmHg}$

- Home diastolic blood pressure monitoring higher than or equal to $85 \mathrm{mmHg}$. 
Studies were excluded if the condition treated was secondary hypertension.

\subsubsection{Types of interventions}

Studies were included if the intervention included one of the following:

- Berberine as single independent herbal extract in any form, e.g., berberine hydrochloride, in a given or calculable dose;

- A preparation made through the combination of multiple independent herbal extracts where the actual content of berberine was specified or possible to estimate;

- Decoctions or extract from a mixture of herbs, where at least one of the herbs was a source of berberine, and where the actual content of berberine was specified or possible to estimate.

Any co-intervention in addition to the experimental intervention and comparator interventions were allowed as long as all arms of the trial received the same co-intervention. To ensure a wider scope of analysis, studies with any control intervention were included.

\subsubsection{Types of outcome measures}

From the eligible studies, it was sought to extract the following outcome measures for all follow-up points after completion of the interventions:

\section{Primary outcomes}

- Fatal and non-fatal cardiovascular events of all types

- Systolic and diastolic blood pressure measures of all types

\section{Secondary outcomes}

- Death from any cause

- Quality of life

- Adverse events. It was sought to distinguish between two types of adverse events: adverse events considered serious and adverse events considered non-serious. Following the definition in the Yellow Card Scheme [24], adverse events were defined as any harmful medical occurrence that results in death, is life threatening, leads to a congenital 
abnormality, results in involved or prolonged inpatient hospitalisation, results in involved persistent or significant disability or incapacity. Adverse events not satisfying these criteria were considered non-serious.

\section{Timing of outcome measurements}

No criteria were imposed on the minimum experimental and comparator intervention duration.

\subsection{Search methods for identification of studies}

The following sources were searched for identification of trials:

- Medline (EBSCOhost) (1946 to 18 April 2020);

- Cumulative Index to Nursing and Allied Health Literature (CINAHL) Plus with Full Text (EBSCOhost) (1937 to 18 April 2020);

- The Allied and Complementary Medicine Database (AMED) (EBSCOhost) (1995 to 18 April 2020);

- $\quad$ Embase (Ovid) (1974 to 18 April 2020);

- Cochrane Central Register of Controlled Trials (CENTRAL) (2020 issue 4).

The keywords used in the searches are reported in Appendix 2. The plants there listed are known sources of berberine. Names were collected through an iterative process during the scoping search, and were found in three reviews $[10,11,18]$.

To increase sensitivity, subject heading searches and keyword searches were used, and subject headings were exploded. Additionally, the only filter used was each database built-in filter for human studies. Reference lists of retrieved papers and reviews on the topic were scrutinised to locate additional relevant citations.

\subsection{Data collection and analysis}

\subsubsection{Selection of studies}

All citations retrieved, after having removed duplicate search results directly in EBSCOhost and Ovid platforms, were exported from the search databases to a RIS format file. This was then 
imported into the reference management software Mendeley Desktop for Linux, where the whole set of citations was further deduplicated. Mendeley was then used for study selection.

Based on Study eligibility criteria, titles and abstracts of all citations retrieved were screened. The full-text articles of potentially relevant titles and abstracts was sourced, with those not in English or Italian translated with Google Translate [25] into English, and then assessed for eligibility. Reasons for exclusion of papers that did not meet the inclusion criteria were recorded.

\subsubsection{Data extraction and management}

Standardised forms for data extraction of items of interest from the included papers were developed in LibreOffice Calc spreadsheet computer program. The forms were designed based on the checklist of items to consider in data collection given in the Cochrane Handbook [26]. Data was extracted for the following items:

- Study design

- $\quad$ Characteristics of participants;

- Experimental and comparator interventions;

- Outcomes and timing, and adverse outcomes;

- Results.

\subsubsection{Assessment of risk of bias in the included studies}

A standardised form for risk of bias assessment at study level was adapted in LibreOffice Calc from the SIGN methodology checklist for controlled trials [27] and companion notes [28]. This tool has been validated, and provides a balance between methodological rigour and practicality of use [29]. There are several other risk of bias assessment tools. For example, the Rob2 is the tool of choice for Cochrane reviews [30]. This tool is comprehensive but extensive in its practical application. For the scope of this review, the SIGN checklist was deemed more appropriate, providing straightforward questions to assess study design elements that contribute to risk of bias. 


\subsubsection{Measures of treatment effect}

It was planned to group effect measures depending on the type of outcomes reported in the included studies. Also, it was planned to extract both baseline and follow-up outcomes for all groups, and effect estimates in the form of follow-up between-groups comparison or change from baseline between-groups comparison, or both, whichever were given in a study [31]. All statistical analysis were carried out with RevMan 5 [32].

\section{Dichotomous data}

It was planned to calculate dichotomous outcomes, e.g., stroke yes/no, as risk ratio (RR) with 95\% confidence interval (CI).

\section{Continuous data}

It was planned to express continuous outcomes (e.g., SBP) as mean difference (MD) with 95\% CI.

\section{Results}

\subsection{Description of studies}

\subsubsection{Results of the search}

Database searches through the computerised strategy listed in Appendix 2 returned 691 citations. Citation screening is summarised in Figure 1 (PRISMA flow diagram). Removing duplicates left 551 citations to screen. Scanning titles and abstracts left 60 citations to assess for eligibility. Fiftytwo were full papers, eight were conference abstracts. Four full-text articles were not retrievable. Scanning of article references retrieved five additional possibly relevant citations. Four were cited in Lan et al. (2015). All were in Chinese, not indexed in the searched databases, of which one fulltext article was retrievable. One more citation was in Tabeshpour et al. [17]full-text article was retrievable. Overall, fifty-six articles were in English, two in Chinese. Forty-three papers and seven conference abstracts were excluded. Reasons for exclusion are in Figure 1. 


\subsubsection{Included studies}

Table 1 summarises features of included studies. Appendix 1 - Characteristics of included studies has full details. Seven papers and one conference abstract met the inclusion criteria [33-40]. They corresponded to seven studies, as the conference abstract [39] referred to the same study of one paper [38], the former not providing additional information to the latter.

Six papers were in English, one in Chinese [33]. Three trials were conducted in Italy [34,37,38], two in Korea [36,40], one in China [33], and one in Pakistan [35]. Two trials were not randomised [34,35]. All trials employed a parallel two-arm design. 
Figure 1. PRISMA flow diagram of study selection process: berberine for the treatment of hypertension.

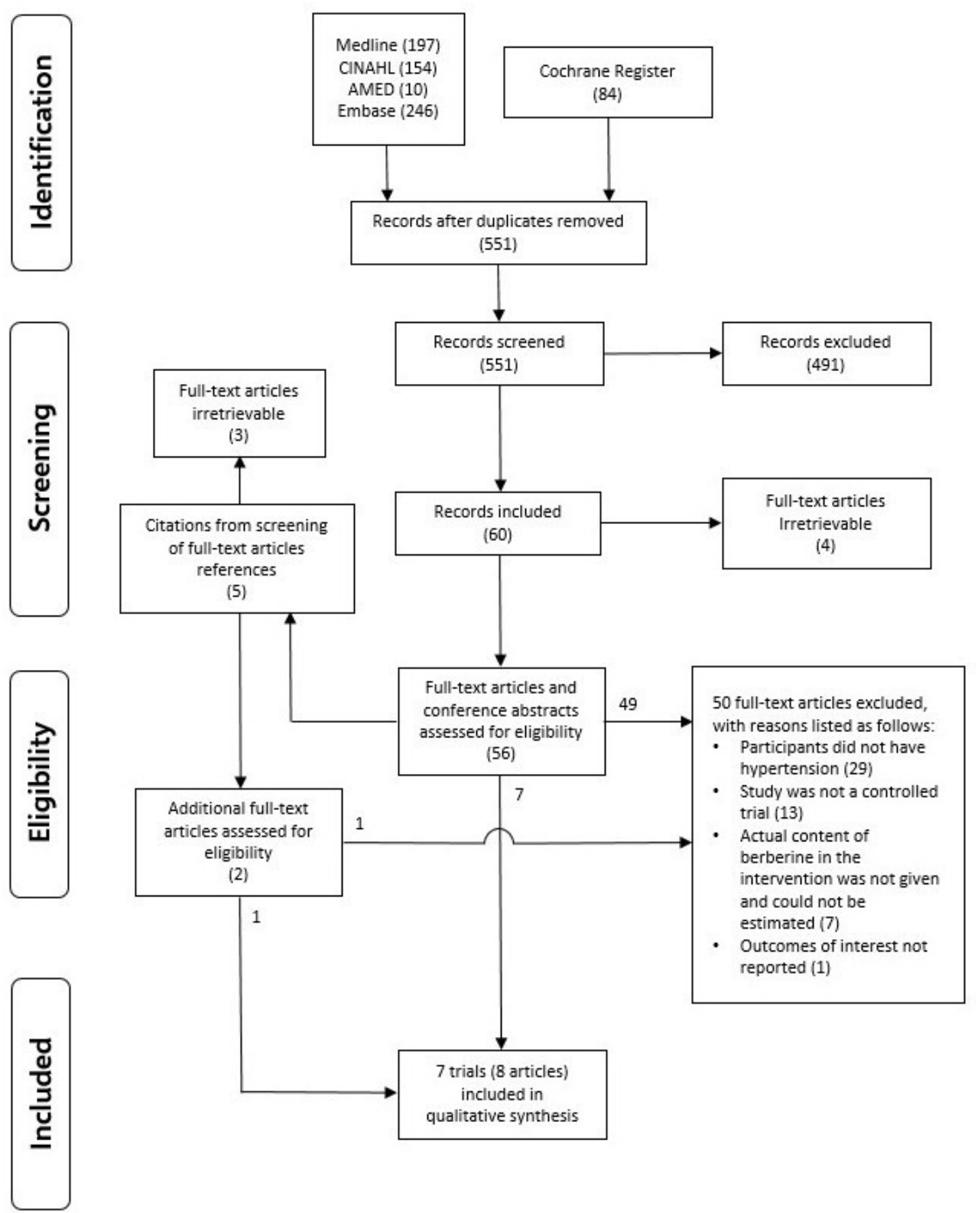

Adapted from [41] 
The primary aim of five trials was the reduction of blood pressure in individuals with hypertension. In one trial the primary aim was to reduce insulin resistance in individuals newly diagnosed with diabetes [35], and in another trial it was to reduce arterial stiffness in individuals with raised brachial pulse wave velocity (baPWV) [36].

\subsubsection{Participants}

A total of 614 individuals with hypertension were included in seven trials. Average sample size was 88 (27 [38] to 200 [35]). Among participants, 200 were recruited in Pakistan, 187 in Italy, 164 in China, and 63 in Korea. Mean participant age was 53 (33 [35] to 65 [40]). One study did not report the number of male and female participants [35]. Among 414 participants of six trials, there were 57\% men (29\% [36] to 85\% [38]). Two trials included inpatients [33,40]; one trial included outpatients [36]; four trials did not specify trial setting [34,35,37,38]. All trials were single-centre.

\subsubsection{Diagnosis}

All participants had hypertension at baseline. All trials enrolled patients who also had one or more comorbidities, i.e., gout [33], hypercholesterolaemia [34], newly diagnosed type 2 diabetes [35], elevated baPWV [36], metabolic syndrome [37], low cardiovascular risk [38], and newly diagnosed stroke [40].

\subsubsection{Interventions}

There were wide variation in the experimental intervention formulations and doses, in comparator interventions, and in duration of interventions. Four different oral preparations were tested. Only two trials tested berberine without any other component [33,35]. One trial tested a proprietary nutraceutical, i.e., a combination of multiple functional foods, herbal extracts, and supplements [34]. Two trials tested a different version of the same proprietary nutraceutical containing one additional ingredient, orthosiphon staminensi, a purported hypotensor [37,38]. Two trials tested a lyophilised herbal extract of Chinese herbs, known as Chunghyul-dan (Qingxue-dan) [36,40]. These studies did not provide the berberine content of their preparation. However, this was made with a standardised procedure. Content was estimated from a trial which tested Chunghyul-dan made with the same standardised procedure, as this study provided Chunghyul-dan berberine percentage by weight [42]. 
Control interventions included amlodipine, meformin, a nutraceutical compound, diet, placebo, and observations only. The duration of treatment varied from two weeks to six months.

\subsubsection{Outcomes}

All included studies reported at least one of blood pressure primary outcomes. No study reported on cardiovascular events, nor on the secondary outcomes death from any cause and quality of life. No study carried out long-term follow-up. Outcomes reported by some studies but not included in this review were not extracted.

All but one study [35] reported some information on adverse events. One study mentioned that interventions were safe [33]; two that there were no adverse events [37,38]; one that two participants withdrew from the experimental group due to dyspepsia and doubling of creatinine kinase level[34]; one that adverse events were absent and there were no statistically significant changes in several measured metabolic parameters [36]; and one that in some participants some symptoms improved, i.e., insomnia, constipation, and pruritus [40].

\subsection{Risk of bias in included studies}

\subsubsection{Overview of risk of bias in included studies}

All studies provided limited details about their design and methodology. Figure 2 summarises answers to individual SIGN quality items. Figure 3 summarises the percentage for answers to each item across all studies. These plots were developed in LibreOffice Calc and adapted from the output formats of the Risk-of-bias VISualization (robvis) tool [43], which does not include the SIGN tool as one of its templates. As all studies were single-centre, SIGN tool item 10, relating to multi-centre studies, was excluded. Justifications for all answers are in Appendix 1 - Characteristics of included studies.

Five studies were RCTs, two were non-randomised controlled trial (NRCT) [34,35]. None reported sample size calculation. All studies pre-specified participant inclusion and exclusion criteria. All studies provided insufficient information to establish if they applied intention-to-treat analysis. Overall, all studies were of low quality. Table 1 'Quality assessment' summarises judgment rationales. 


\subsubsection{Allocation}

Only one study reported randomisation method, described as random number tables [33]. No study reported concealment method.

\subsubsection{Blinding}

One of the study mentioned blinding without other details [37]. The remaining studies either were described as open-label, or they were likely open-label, as blinding was not mentioned or their characteristics suggested non-blinding, e.g., no placebo.

\subsubsection{Attrition}

Two studies did not report loss to follow-up [33,36]. One study had serious drop-out rate of 30\% [40]. In the remaining studies drop-out rate was acceptable.

\subsubsection{Other sources of bias}

\section{Selective reporting}

SIGN quality assessment tool does not include selective reporting, i.e., reporting bias, hence it was assessed separately. Table 1 'Outcome measures' and 'Effect estimates' summarises the results reported.

No protocol registrations matching any of the studies were found in either ClinicalTrials.gov or World Health Organization International Standard Randomised Controlled Trial Number registry. Selective reporting judgments were made based on study stated outcomes in method section and reported outcomes in result section of papers.

Three studies carried out at least one statistical comparisons between experimental and comparator group $[35,37,40]$. These were also studies that, in this review statistical analyses, showed significant effect estimates. The remaining studies reported statistical analyses only within groups $[33,34,36,38]$. All of these studies but one [34] were also studies that did not show significant effect estimates. Detailed analysis is in Outcome reporting bias. 


\section{Source of funding}

SIGN quality assessment tool does not include source of funding bias, hence it was also assessed separately. Details are in Table 1 "Source of funding”. One study had high risk of bias, as the experimental intervention manufacturer funded paper preparation [34]. Two papers stated that paper preparation did not require sources of funding $[37,38]$. The remaining papers left funding unreported.

\subsection{Effects of interventions}

There was no data on cardiovascular events, death from any cause, and quality of life. All papers reported on blood pressure. No study reported serious adverse events.

\subsubsection{Statistical analyses in included studies}

No study reported effect estimates and precision. Three studies reported P values for estimates between groups: one compared experimental group follow-up SBP and DBP to those of comparator group [35]; two compared experimental group SBP and DBP change from baseline to those of comparator group $[37,40]$. All other studies reported only within-group comparisons.

\subsubsection{Statistical analyses in the review}

The Consolidated Standards of Reporting Trials (CONSORT) suggests that effect estimates should be calculated through between-groups values, with their precision given as 95\% Cis [44]. Follow-up values were used for estimates, or, when reported, change from baseline if the former were unavailable. All studies reported outcomes as mean and standard deviation in mmHg, allowing to calculate effect estimates as mean difference.

Effect estimates could not be calculated for one of two trials that did not report comparator group follow-up values, nor change from baseline values [36]. For the other trial, follow-up measures in comparator group were accurately estimated from a chart in the paper [34]. 
Figure 2. "Traffic light" plot of SIGN checklist item-level judgments for each study.
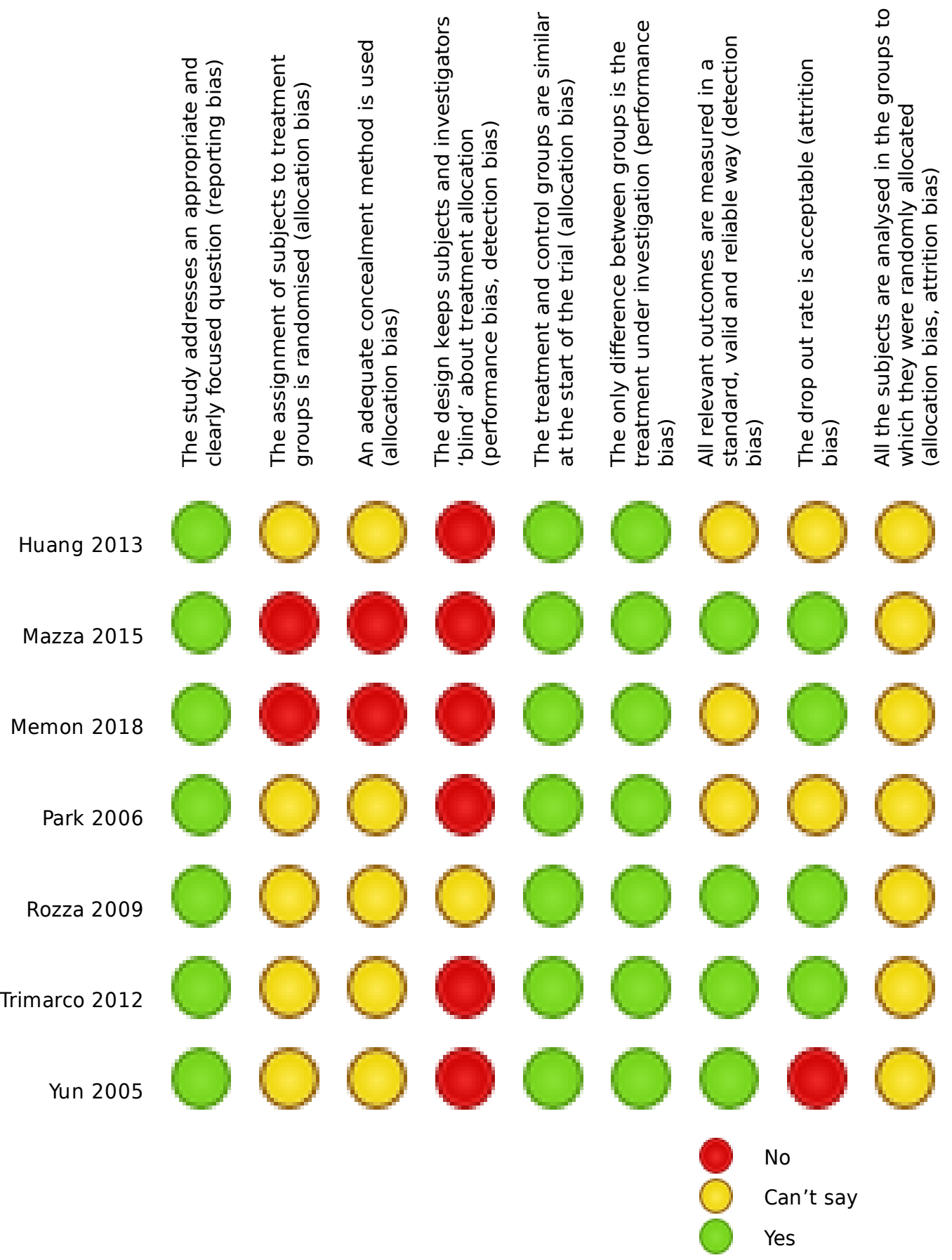

Adapted from the output format of the Risk-of-bias VISualization (robvis) tool [43]. 
Figure 3. Bar plot of the distribution of judgments within each SIGN checklist item.

The study addresses an appropriate and clearly focused question (reporting bias)

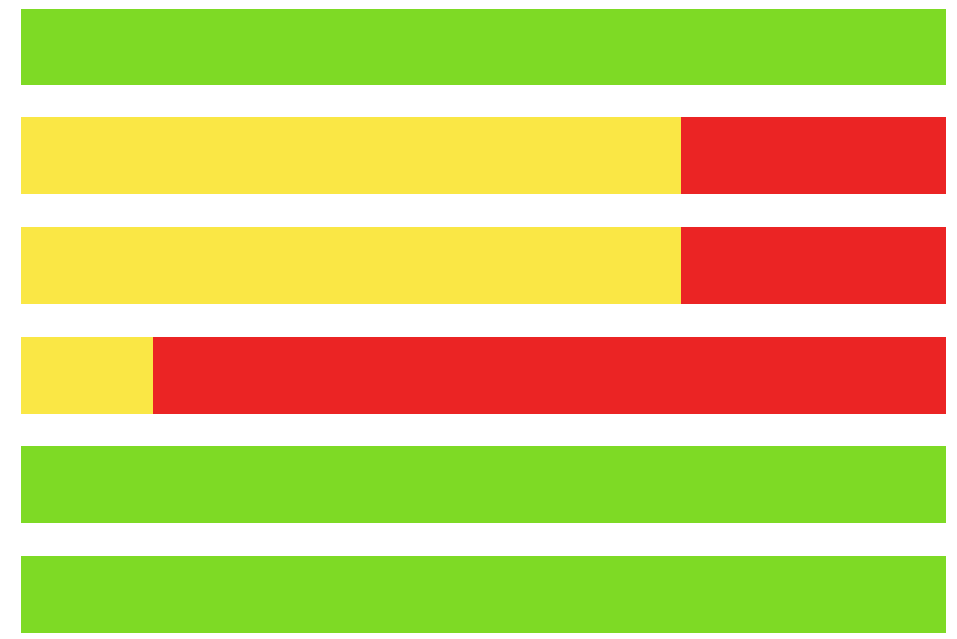

The assignment of subjects to treatment groups is randomised (allocation bias)

An adequate concealment method is used (allocation bias)

The design keeps subjects and investigators 'blind' about treatment allocation (performance bias, detection bias)

The treatment and control groups are similar at the start of the trial (allocation bias)

The only difference between groups is the treatment under investigation (performance bias)

All relevant outcomes are measured in a standard, valid and reliable way (detection bias)

The drop out rate is acceptable (attrition bias)

All the subjects are analysed in the groups to which they were randomly allocated (allocation bias, attrition bias)
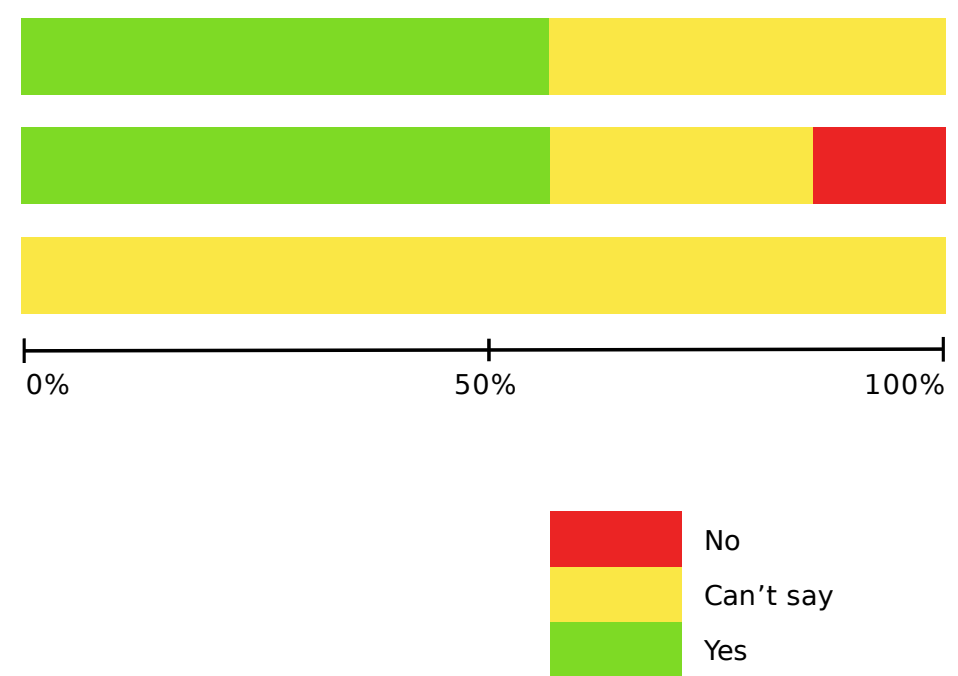

Adapted from the output format of the Risk-of-bias VISualization (robvis) tool [44]. 
Table 1. Summary of features of included studies answering the review question: does treatment with berberine reduce blood pressure and cardiovascular events in adults with primary hypertension?

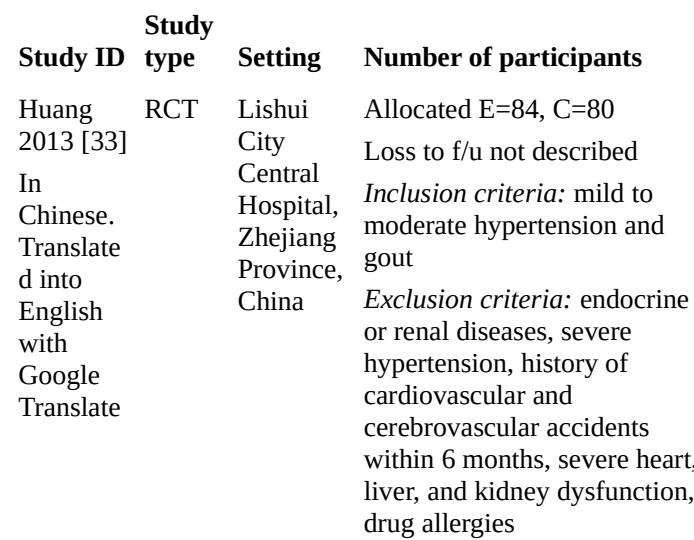

Mazza NRCT Hypertens Allocated E=66, $\mathrm{C}=66$ 2015 [34] ion -
ion
At $\mathrm{f} / \mathrm{u} \mathrm{E}=64, \mathrm{C}=66$
setting in $\mathrm{C}$ group age and gender
matched

Inclusion criteria: patients

with hypertension and

hypercholesterolaemia

Exclusion criteria: severe

hypertension, secondary

hypertension, diabetes

mellitus, neoplastic or hepatic

disease, chronic heart or rena

failure, positive history or

clinical signs of ischemic heart
disease, severe obesity,

disabling diseases such as

dementia or inability to

cooperate, pregnancy or

breastfeeding, antihypertensive

and/or lipid-lowering drug

treatment, and organ damage

(left ventricular hypertrophy

diagnosed by

electrocardiogram, carotid

plaque or albuminuria) due to

hypertension.

\section{Participants Experimental Comparator Length of Outcome}

\section{Pharacteristics intervention intervention follow-up measures Effect estimates}

Hospital Berberine $\mathrm{HCl}$

Amlodipine

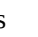

98 males and times a day in (Zhejiang

66 females addition to Hongyuan

Age 42-74 comparator Pharmaceutic

years

$\begin{array}{ll}61.1 \pm 2.8 & \text { Co., Ltd.) } 5 \\ \text { mg oral twice }\end{array}$

mg oral twice
a day, plus

colchicine 1

mg oral three

times a day

for patients

with acute

with acute

allopurinol 50

mg oral twice

a day for

patients with

chronic gout

Males 54.5\% Armolipid Plus Age $56.0 \pm 6.4$ years

(Rottapharm
SpA, a MEDA
Company) one
tablet oral once

Written

\section{2 weeks SBP,}

$\begin{array}{lll}\text { prescription } & \text { run-in } & \text { DBP. } \\ \text { for a } & \text { period, } & \text { systolic }\end{array}$

standardised

tablet oral once

daily in the

Mediterranea interventio dia

systolic
and

$10.7 \pm 18.2$ vs $99.1 \pm 5.4$ 5 $81.5 \pm 0.05$; $\mathrm{C}$ :

bedtime in

addition to high intake of

$\mathrm{n}$ diet

$\mathrm{n}$ for 6

day $24 \mathrm{~h}$, night $24 \mathrm{~h}, \mathrm{p}<0.05)$.

comparator fish, fruits,

Note: ArmoLipid legumes,

Plus is a food olive oil,

supplement unrefined

combining whole grains

natural

and a

ingredients moderate

containing red intake of lea

yeast rice $200 \mathrm{mg}$ meats and

(equivalent of

$3 \mathrm{mg}$ of

monacolin $\mathrm{K}$ ),

policosanol

10mg, berberine

$500 \mathrm{mg}$, folic acid

$0.2 \mathrm{mg}$,

astaxanthin

$0.5 \mathrm{mg}$, and

coenzyme Q10

$2 \mathrm{mg}$
SBP, DBP W

both $\mathrm{E}$ and $\mathrm{C}$ group, follow-up SDB and DBP were significantly lower than baseline values (E: 127.6 $\pm 12.5 \mathrm{mmHg}$ vs

$155.8 \pm 18.2 \mathrm{mmHg} \mathrm{p}<0.05,81.5 \pm$

$132.1 \pm 18.31 \mathrm{mmHg}$ vs $157.3 \pm 22.8 \mathrm{mmHg}$ that

$\mathrm{p}<0.05,83.5 \pm 5.2 \mathrm{mmHg}$ vs $99.5 \pm \quad$ interventio

$6.1 \mathrm{mmHg} \mathrm{p}<0.05)$.

n was safe

(E-C):

SBP: $-4.50[-9.32,0.32]$

DBP: -2.00[-4.56, 0.56]

Article Low quality only the change from baseline of systolic events: two processin High risk of

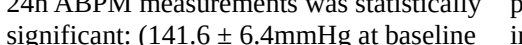
v. $136.2 \pm 4.8 \mathrm{mmHg}$ at follow-up;

Quality

Adverse Source of assessment

funding (SIGN rating) Additional comments

Not stated Low quality Between groups

High risk of comparisons not given

reporting bias. Paper reports that at $\mathrm{f} / \mathrm{u} \mathrm{E}$ Strengths: $\quad$ and $\mathrm{C}$ outcomes were no

moderate group significantly different

size, The study primary aim was

randomisation to investigate the effect on described as hypertension of

random number amlodipine combined with tables. berberine

Weaknesses: no

placebo, likely

$24 \mathrm{~h}$, For $\mathrm{C}$ group, all the difference measures

ABPM pre- and post-intervention were not

statistically significant. Post-intervention

values for $\mathrm{C}$ group are not given in the

paper

It was possible to calculate mean

differences between groups after having

graphically estimated C group follow-up

values.

Calculated mean differences for $\mathrm{f} / \mathrm{u}$ values (E-C):

Mean systolic 24h-ABPM: 3.40 [-5.48, -

1.32]

Mean diastolic 24h-ABPM: 0.90 [-0.28, 2.08] in $\mathrm{E}$ articipants g charges

C group outcome values and between-groups

omparisons not given in the paper

withdrawn study detection, and Primary aim of the study from the were reporting bias was to investigate the

study due funded by Strengths: Low effect of nutraceuticals on to side Rottaphar drenghs.

effects (one m SpA, a Weaknesses: no pressure control in subjects due to a MEDA Weaknesses. no with elevated blood doubling in Company, randomisation; pressure and cholesterol Conza, no placebo; levels

due to manufact moderate group

dyspepsia). urer of size

the tested

nutrace
cal

compoun

d. High

risk of

funding

bias. 
Study

\begin{tabular}{|c|c|c|c|c|c|c|c|}
\hline Study ID & type & Setting & Number of participants & characteristics & intervention & intervention & follow-up \\
\hline $\begin{array}{l}\text { Memon } \\
2018 \text { [35] }\end{array}$ & NRCT & $\begin{array}{l}\text { Tertiary } \\
\text { care } \\
\text { hospital, } \\
\text { Departme } \\
\text { nt of } \\
\text { Medicine, } \\
\text { Liaquat } \\
\text { Universit } \\
\text { y of } \\
\text { Medical } \\
\text { and } \\
\text { Health } \\
\text { Sciences, } \\
\text { Jamshoro/ } \\
\text { Hyderaba } \\
\text { d, } \\
\text { Pakistan, } \\
\text { from } \\
\text { March } \\
2016 \text { to } \\
\text { January } \\
2017\end{array}$ & $\begin{array}{l}\text { E=100, C=100 } \\
\text { C group age and gender } \\
\text { matched } \\
\text { No loss to f/u. } \\
\text { Inclusion criteria: subjects } \\
\text { with newly diagnosed type } 2 \\
\text { DM cases of age } \geq 25 \text { years } \\
\text { taking drug metformin. } \\
\text { Exclusion criteria: subjects } \\
\text { with type } 2 \text { DM taking } \\
\text { sulfonylurea, herbal drugs, } \\
\text { HMG-CoA reductase } \\
\text { inhibitors, and multivitamin } \\
\text { pills and insulin, subjects with } \\
\text { type } 2 \text { DM with diabetic } \\
\text { complications, and subjects } \\
\text { with type } 2 \text { DM with } \\
\text { concomitant chronic viral } \\
\text { hepatic disorders, coronary } \\
\text { ischemic heart disease, chronic } \\
\text { kidney disease, and pregnancy. }\end{array}$ & $\begin{array}{l}\text { Age E: } 33.4 \pm \\
2.96 \text { years, C: } \\
33.26 \pm 2.6 \\
\text { years, }=0.81 \\
\text { No significant } \\
\text { differences for } \\
\text { most measured } \\
\text { parameters } \\
\text { LDL-C and } \\
\text { HDL-C levels } \\
\text { where } \\
\text { significantly } \\
\text { different }\end{array}$ & $\begin{array}{l}\text { Berberine 500mg } \\
\text { oral three times a } \\
\text { day }\end{array}$ & $\begin{array}{l}\text { Metformin } \\
\text { (Glucophage, } \\
\text { Merck } \\
\text { Pharmaceutic } \\
\text { als) 500mg } \\
\text { oral three } \\
\text { times a day }\end{array}$ & 3 months \\
\hline $\begin{array}{l}\text { Park } 2006 \\
\text { [36] }\end{array}$ & RCT & $\begin{array}{l}\text { Outpatien } \\
\text { ts visiting } \\
\text { the } \\
\text { Cardiovas } \\
\text { cular } \\
\text { Center of } \\
\text { Kyung } \\
\text { Hee } \\
\text { Universit } \\
\text { y } \\
\text { Kangnam } \\
\text { Korean } \\
\text { Hospital } \\
\text { between } \\
\text { Novembe } \\
\text { r 2003 } \\
\text { and } \\
\text { October } \\
2004\end{array}$ & $\begin{array}{l}\text { Allocated E=20, C=15 } \\
\text { Loss to follow-up not } \\
\text { described } \\
\text { Inclusion criteria: baPWV } \\
\text { higher than } 1400 \mathrm{~cm} / \mathrm{s} \\
\text { Exclusion criteria: use of } \\
\text { hormone replacement therapy } \\
\text { in the } 2 \text { months prior to the } \\
\text { study, use of anti- } \\
\text { hyperlipidemic agents or } \\
\text { steroids within } 6 \text { months, and } \\
\text { the presence of hepatic or renal } \\
\text { diseases }\end{array}$ & $\begin{array}{l}\text { Gender (male } \\
\text { vs female) E: } 6 \\
\text { vs 14, C: } 4 \text { vs } \\
\text { 11, p=0.863 } \\
\text { Age E: } 61.4 \pm \\
9.6 \text { years, C: } \\
63.4 \pm 10.5 \\
\text { years p=0.644 } \\
\text { No statistically } \\
\text { significant } \\
\text { differences } \\
\text { between groups } \\
\text { at baseline in } \\
\text { terms of SBP, } \\
\text { DBP, and } \\
\text { baPWV }\end{array}$ & $\begin{array}{l}\text { Chunghyul-dan } \\
\text { (Qingxue-Dan) } \\
600 \mathrm{mg} \text { oral three } \\
\text { times a day. For } \\
\text { this review, the } \\
\text { content of } \\
\text { berberine is } \\
\text { calculated as } 4 \% \\
\text { of total } \\
\text { preparation using } \\
\text { estimate in } \\
\text { [43]. Hence, total } \\
\text { estimated } \\
\text { berberine daily } \\
\text { dose was 24mg } \\
\text { three times a day }\end{array}$ & $\begin{array}{l}\text { Observations } \\
\text { only }\end{array}$ & 8 weeks \\
\hline
\end{tabular}

Quality

Adverse Source of

\section{events funding (SIGN rating)}

Adverse Not stated Low quality

SBP and The paper reports between-groups

DBP were comparison. At follow-up, both SBP and not stated DBP in E group were significantly lower discussed

main than those in $\mathrm{C}$ group (but see note below): in the

outcomes $131.4 \pm 15.2 \mathrm{mmHg}$ vs $143.3 \pm 19.0 \mathrm{mmHg}$ paper

in the $\quad \mathrm{p}=0.001,70.61 \pm 13.65 \mathrm{mmHg}$ vs $72.57 \pm$

study. $\quad 11.2 \mathrm{mmHg} \mathrm{p}=0.03$

However, Calculated mean differences for $\mathrm{f} / \mathrm{u}$ values measures (E-C):

are $\quad$ SBP: $-11.87[-16.64,-7.10]$

for pre- DBP: $-1.96[-5.42,1.50]$

and post- Note: DBP difference between group at $\mathrm{f} / \mathrm{u}$

interventi is NS. Calculated significant level $p=0.27$,

on for not $\mathrm{p}=0.03$ as paper reports

High risk of
allocation,

performance,

performance,

bias

Strengths:

moderate group

size, no loss to

f/u

Weaknesses: no

randomisation,

likely open-

label

SBP and For E group SBP and DBP are given at DBP were baseline $(152.9 \pm 22.0 \mathrm{mmHg}$ and $91.3 \pm$ There were Not stated Low quality not $\quad 8.0 \mathrm{mmHg}$ ) and follow-up (137.6 \pm 13.3 primary $\mathrm{mmHg}$ and $87.2 \pm 8.2 \mathrm{mmHg}$ ), and the no clinical High risk of

differences were not statistically significant. observed $\begin{array}{lll} & \text { For C group only baseline SBP and DBP } & \text { during the } \\ \text { study, } & \text { values are given in the paper. } & 8 \text { weeks of }\end{array}$

baPWV Between-groups comparisons of SBP and treatment. was the DBP were not given in the paper, and effect main estimates and their precision were also not no outcome reported. It was not possible to calculate effect significant estimates and their precision as mean changes in differences between groups could not be E group calculated. and f/u

values for

the

following monitored AST, ALT, BUN, and High risk of

Primary aim of the study performance, Chunghyul-dan (Qingxuedetection, and Dan) on arterial stiffness in reporting bias; patients with raised unclear risk of baPWV allocation and allocation and Strengths: none Weaknesses: no placebo, small short duration Pary aim of the study effects of berberine on serum methylglyoxal and sulin resistance in newly diagnosed type 2 diabetic patients

,


Study

Study ID type Setting Number of participants

Rozza RCT Italy

2009 [37]

Trimarco RCT Italy 2012 [38]

No loss to follow-

and diagnosec

who were pregnant or

breastfeeding women and

patients treated with

lowering drugs

Allocated $\mathrm{E}=20, \mathrm{C}=10$

At $\mathrm{f} / \mathrm{u} \mathrm{E}=18$ and $\mathrm{C}=9$
Participants Experimental

characteristics

Gender (M/F Armolipid Prev: Placebo

\%) E: 67/33, C: Armolipid Plus

73.3/26.7 with the addition

Inclusion criteria: subjects of

both sexes aged 18-75 years

Exclusion criteria: subjects

antihypertensive and/or lipid-

10.1 4 ys, $\mathrm{C}:$ staminensi (dose

$45.5 \pm 10.8$ not given)

years, NS Armoloipid Plus

At baseline constituents

there were no given in the

included study

significant above [39]

differences Study does not

between all specify how

measured many tablets of

parameters, the preparation or

including SBP, how often it was

and DBP administered

Inclusion criteria: both

genders, aged between 18 an

75 years, with grade 1

essential hypertension and low

cardiovascular risk

Exclusion criteria: pregnant

breastfeeding women and

patients treated with

antihypertensive and/or lipid

lowering drugs Armolipid Prev Plus

:15/3, C: 8/1, constituents Armoloipid given in the Plus

Age E:45.61 \pm included study constituents 12.8 years, C: above [37]. given in the $47.56 \pm 6.0 \quad$ Study does not included $\begin{array}{lll}\text { At baseline } & \text { specify how } & \text { study } \\ \text { many tablets of } & \text { [34] }\end{array}$

there were no the preparation or Study does statistically how often it was not specify administered how mon how many Dietary advice tablets of the

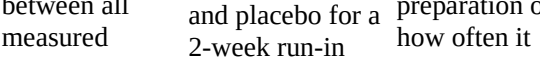
parameters, period was including age, $\quad$ administered gender, SBP, Dietary DBP, and 24h- advice and ABPM placebo for a 2-week run-in period
Quality

Adverse Source of assessment

events funding (SIGN rating) Additional comments

The paper No Low quality Primary aim of the study

reports no sources of Unclear risk of was to investigate

$\begin{array}{llll}\text { run-in } & \text { DBP were comparison of change from 2-week run-in } & \text { reports no } & \text { sources of } \\ \text { period, } & \text { part of the to 6-week follow-up, showing that E group } & \text { adverse } & \text { funding allocation, }\end{array}$

then primary had, compared to C group, a significantly outcomes, were used performance,

reduction of blood

interventio outcome higher SBP reduction $(-19.6 \pm 9.7 \mathrm{mmHg}$ vs but does to assist perferm

$n$ for 6 measures $-3.6 \pm 8.1 \mathrm{mmHg} ; \mathrm{p}<0.0001$ ) and DBP not give in the detection, and treated with nutraceuticals

months reduction $(-13.6 \pm 5.5 \mathrm{mmHg}$ vs $-2.3 \pm$ details preparatio attrition bias

5.3mmHg; $\mathrm{p}<0.0001)$. Effect estimates and $\quad \mathrm{n}$ of the Strengths:

$\begin{array}{lll}5.3 \mathrm{mmHg} ; \mathrm{p}<0.0001) \text {. Effect estimates and } & \text { paper } & \text { placebo } \\ \text { their precision were not reported. } & \end{array}$

Calculated mean differences for changes controlled

from 2-week run-in (E-C):

SBP: $-16.00[-22.4,-9.60]$

Weaknesses:

small group

DBP: $-11.30[-15.17,-7.43]$

size

Calculated mean differences for $\mathrm{f} / \mathrm{u}$ values

(E-C):

SBP: $-11.80[-18.73,-4.87]$

DBP: $-11.10[-14.74,-7.46]$

4 weeks 24h- In E group, at 4-week follow-up all

Pap

No

Low quality

ABPM, measures had significant reduction from

daytime baseline, for both systolic and diastolic 24h- there was a funding High risk of

ABPM, ABPM: $130.98 \pm 7.2$ vs $135.87 \pm \quad$ lack of were used reporting, and

and night- $8.2 \mathrm{mmHg} ; \mathrm{p}=0.0001 ; 83.74 \pm 3.8$ vs 87.34 adverse to assist detection bias

$\begin{array}{lll}\text { time } & \pm 4.4 \mathrm{mmHg}, \mathrm{p}=0.0001 \text {; daytime: } 137.22 \pm \text { reactions in the } \\ \text { ABPM } & 8.2 \mathrm{vs} 141.82 \pm 8.1 \mathrm{mmHg} \mathrm{p}=0.002,89.27\end{array}$

were the \pm 4.5 vs $92.83 \pm 4.4 \mathrm{mmHg}, \mathrm{p}=0.001$; night- No other preparatio allocation and

primary the $115.30 \pm 8.5$ vs $121.46 \pm 10.8 \mathrm{mH}$ details are

$\begin{array}{llll}\text { primary } & \text { time: } 115.30 \pm 8.5 \text { vs } 121.46 \pm 10.8 \mathrm{mmHg} \text {, given } & \text { paper } & \text { attition bias } \\ \text { outcome } & \mathrm{p}=0.008,70.31 \pm 5.6 \text { vs } 74.01 \pm & & \text { Strengths: none }\end{array}$

measures $7.5 \mathrm{mmHg}, \mathrm{p}=0.037$

In $\mathrm{C}$ group, measures at baseline and at 4

week follow-up were not significantly

different.

Weaknesses:

small group

size, short

duration

Between-groups estimates and effect

estimates and their precision were not

given.

Calculated mean differences for $\mathrm{f} / \mathrm{u}$ values

(E-C):

Systolic 24h-ABPM: -0.47 [-7.06, 6.12]

Diastolic 24h-ABPM: -3.35 [-9.99, 3.29]

Systolic daytime ABPM: -0.99 [-7.60, 5.62]

Diastolic daytime ABPM: -3.59 [-9.70,

2.52]

Systolic night-time ABPM: -0.70 [-8.83,

7.43]

Diastolic night-time ABPM: -2.78 [-11.16,

5.60]
Primary aim of the study was to investigate th

duction of blood

pressure in patients with

yypertension treated with a

nutraceutical 
Study

Study ID type Setting Number of participants

Yun 2005 RCT Departme Recruited E=20, C=20

[40]

$\begin{array}{ll}\text { nt of } & \text { At follow-up E=15; C=13 } \\ \text { Cardiovas } \\ \text { cular and Inclusion criteria: subjects } \\ \text { Neurologi } \\ \text { hospitalised } 10 \text { days after } \\ \text { stroke with stage } 1\end{array}$

Neurologi hospitalised 10 days after

stroke with stage

$\begin{array}{ll}\text { Diseases } & \text { hypertension } \\ \text { (Stroke Exclusion criteria: subjects }\end{array}$

$\begin{array}{ll}\text { (Stroke } & \text { Exclusion criteria: subjects } \\ \text { Center), } & \text { who were taking hypotensors, }\end{array}$

Center), who were taking hypotens
Hospital

of diseases, or experienced

Oriental cardiovascular disease within

Medicine, three months

Kyung

Hee

Medical

Center,

Seoul,

Korea,

June 2003

to 31

March

2004
Participants Experimental Comparator Length of Outcome

\section{characteristics intervention intervention follow-up measures Effect estimates}

Gender (males, Chunghyul-dan No

C: 4 (30.8), NS 1200mg oral

Age E: $64.8+$ once a day. For

9.59 , years $\mathrm{C}$ : this review, the

$65.62 \pm 9.77 \quad$ content of

years, NS berberine is

At baseline of total

there were no preparation using

statistically estimate in [42].

differences Hence, total

differences estimated

measured berberine daily

measured dose was $48 \mathrm{mg}$

parameters, once a day

including

systolic and

ABPM and values are given in the paper for both

diastolic groups

24h- $\quad$ The only statistically significant effect was

ABPM in E group for change from baseline of

were part systolic 24h-ABPM: $141.37 \pm 8.96 \mathrm{mmHg}$

of the vs $132.28 \pm 9.46 \mathrm{mmHg} p=0.03$,

pinmary corresponding to mean change from

outcomes baseline $9.09 \pm 8.73 \mathrm{mmHg}$.

Estimate is given for SBP changes from

baseline between $\mathrm{E}$ and $C$ group: $9.09 \pm$

$8.73 \mathrm{mmHg}$ vs $1.75 \pm 6.90 \mathrm{mmHg}$

Effect estimates and their precision were

not given.

Calculated mean differences for $\mathrm{f} / \mathrm{u}$ values (E-C):

Systolic 24h-ABPM: -4.99 [-11.81, 1.83]

Diastolic 24h-ABPM: 2.06 [-3.27, 7.39]

Calculated mean differences for changes from baseline (E-C)

Systolic 24h-ABPM: -7.34 [-13.14, -1.54]

Diastolic 24h-ABPM: -0.70 [-5.28, 3.88]
Quality

Adverse Source of assessment

events funding (SIGN rating) Additional comments

Paper Not stated Low quality

reports that High risk of

Primary aim of the study

no adverse attrition,

found, and performance, (Qingxue-dan) on blood

and dection patients just diagnosed

subjects

showed

improvem

nt of

symptoms

insomnia

one

constipatio

pruritus)

bias patients just diagnosed

Unclear risk of hipertension

allocation bias

Strengths: none

Weaknesses: no

placebo, $30 \%$

up, very short

duration

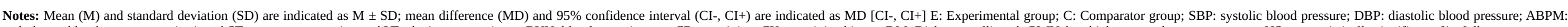

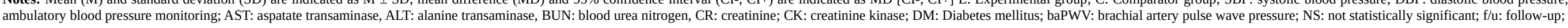

Adapted from 'Example of an evidence table for intervention studies' [23]. 


\subsubsection{Meta-analysis}

Intervention heterogeneity made a meta-analysis inappropriate for most study groups. Only the two studies on Chunghyul-dan were broadly similar [36,40], and a meta-analysis would have been appropriate. However, one study [36] did not report comparator group follow-up or change from baseline values, also preventing meta-analysis. Therefore, results are presented per intervention and for individual studies.

\subsubsection{Berberine as individual ingredient}

\section{Amlodipine plus berberine versus amlodipine}

One RCT compared amlodipine plus berberine (900mg daily) to amlodipine in individuals with hypertension and gout [33]. Within both groups, follow-up SDB and DBP were significantly lower than the respective baseline values. The study did not report between-groups comparison for either follow-up or change from baseline of SBP and DBP values. Effect estimates were -4.50 [-9.32, 0.32] mmHg for SBP (Figure 4) and -2.00 [-4.56, 0.56] mmHg for DBP (Figure 5), both not statistically significant.

Figure 4. Forest plot comparison: amlodipine plus berberine versus amlodipine; outcome: SBP at follow-up

\begin{tabular}{|c|c|c|c|c|c|c|c|c|c|c|}
\hline \multirow[b]{2}{*}{ Study or Subgroup } & \multicolumn{3}{|c|}{ Amlodipine plus Berberine } & \multicolumn{3}{|c|}{ Amlodipine } & \multirow{2}{*}{$\begin{array}{l}\text { Mean Difference } \\
\text { IV, Fixed, } 95 \% \mathrm{CI}\end{array}$} & \multirow{2}{*}{\multicolumn{3}{|c|}{$\begin{array}{l}\text { Mean Difference } \\
\text { IV, Fixed, } 95 \% \mathrm{CI}\end{array}$}} \\
\hline & Mean & SD & Total & Mean & SD & Total & & & & \\
\hline Huang (2013) & 127.6 & 12.5 & 84 & 132.1 & 18.31 & 80 & $-4.50[-9.32,0.32]$ & \begin{tabular}{l|l}
-2 \\
2
\end{tabular} & 干 & \\
\hline
\end{tabular}

Figure 5. Forest plot comparison: amlodipine plus berberine versus amlodipine; outcome: DBP at follow-up

\begin{tabular}{|c|c|c|c|c|c|c|c|c|c|c|}
\hline \multirow[b]{2}{*}{ Study or Subgroup } & \multicolumn{3}{|c|}{ Amlodipine plus berberine } & \multicolumn{3}{|c|}{ Amlodipine } & \multirow{2}{*}{$\begin{array}{l}\text { Mean Difference } \\
\text { IV, Fixed, } 95 \% \mathrm{Cl}\end{array}$} & \multirow{2}{*}{\multicolumn{3}{|c|}{$\begin{array}{l}\text { Mean Difference } \\
\text { IV, Fixed, } 95 \% \mathrm{Cl}\end{array}$}} \\
\hline & Mean & SD & Total & Mean & SD & Total & & & & \\
\hline Huang (2013) & 81.5 & 10.7 & 84 & 83.5 & 5.2 & 80 & $-2.00[-4.56,0.56]$ & \begin{tabular}{l|l}
+1 \\
\end{tabular} & - & \\
\hline
\end{tabular}

\section{Berberine versus metformin}

One NRCT investigated berberine (1500mg daily) effect on insulin resistance and serum methylglyoxal compared to metformin in newly diagnosed patients with type 2 diabetes [35]. SBP 
and DBP were not outcomes of the study. Nonetheless, they were measured at baseline and followup. The study reported that follow-up SBP and DBP in experimental group were significantly lower than comparator group values. Effect estimates were $-11.87[-16.64,-7.10]$ mmHg for SBP (Figure 6), statistically significant, and $-1.96[-5.42,1.50] \mathrm{mmHg}$ for DBP (Figure 7), not significant. The paper, by miscalculating the P value, mistakenly reported follow-up DBP difference between groups as significant.

Figure 6. Forest plot comparison: berberine versus metformin; outcome: SBP at follow-up

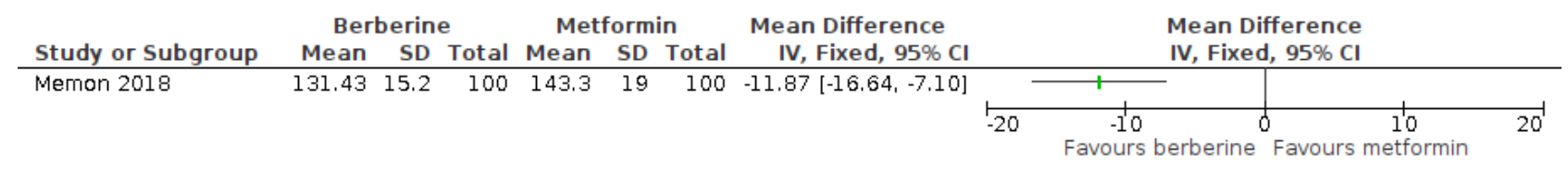

Figure 7. Forest plot comparison: berberine versus metformin; outcome: DBP at follow-up

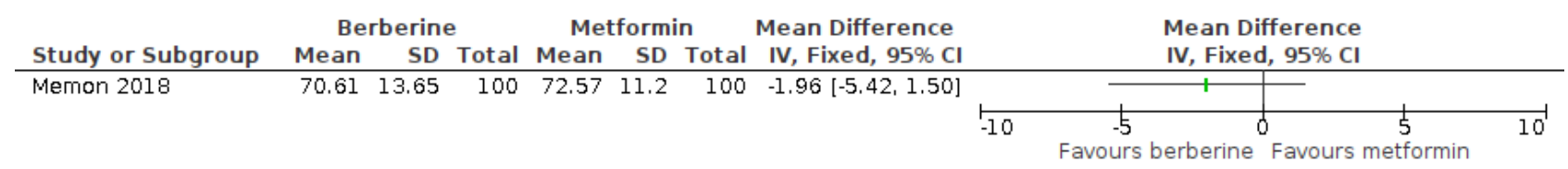

\subsubsection{Proprietary preparations containing berberine}

One NRCT compared the nutraceutical Armolipid Plus in addition to dietary advice to dietary advice only [34]. Two RCTs compared the proprietary nutraceutical Armolipid Prev, one to placebo [37], and one to Armolipid Plus [38]. Both nutraceuticals are made by the Italian pharmaceutical company Rottapharm SpA (a MEDA Company). Armolipid Plus combines natural ingredients, i.e., $500 \mathrm{mg}$ berberine, red yeast rice (3mg of monacolin $\mathrm{K}$ ), 10mg policosanol, 0.2 folic acid, 0.5 astaxanthin, and 2mg coenzyme Q10. Armolipid Prev has orthosiphon staminensi added to Armolipid Plus ingredients. The two studies investigating Armolipid Prev did not specify the dose of orthosiphon staminensi. Of the three studies, only one provided actual doses of ingredients [34].

\section{Armolipid Plus plus dietary prescription versus dietary prescription only}

In the NRCT investigating Armolipid Plus [34], the experimental intervention included the nutraceutical plus a written prescription for a Mediterranean diet. The comparator intervention included only the dietary prescription. 
The study reported that, of all eight outcome measures, i.e., clinic SBP and DBP, and mean systolic and diastolic 24h-, daytime, and night-time ABPM, the only statistically significant change within the experimental group was for systolic 24h-ABPM. There were no statistically significant changes within the comparator group.

The study did not report comparator follow-up values, nor reported between-groups comparisons. However, it reported a chart of comparator group baseline and follow-up mean systolic and diastolic 24h-ABPM. An accurate estimates of actual values was obtained graphically through LibreOffice Draw computer program. The effect estimates were then calculated as -3.40 [-5.48,-1.32] mmHg for systolic 24h-ABPM (Figure 8), statistically significant, and $0.90[-0.28,2.08] \mathrm{mmHg}$ for diastolic 24-ABPM (Figure 9), not significant.

Figure 8. Forest plot comparison: Armolipid Plus plus diet versus diet; outcome: systolic 24h-ABPM at follow-up

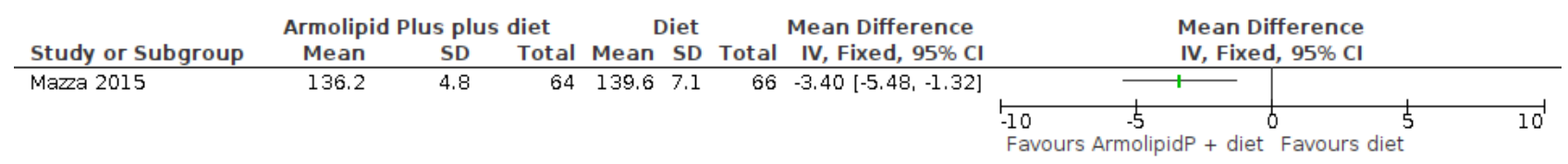

Figure 9. Forest plot comparison: Armolipid Plus plus diet versus diet; outcome: diastolic 24h-ABPM at follow-up

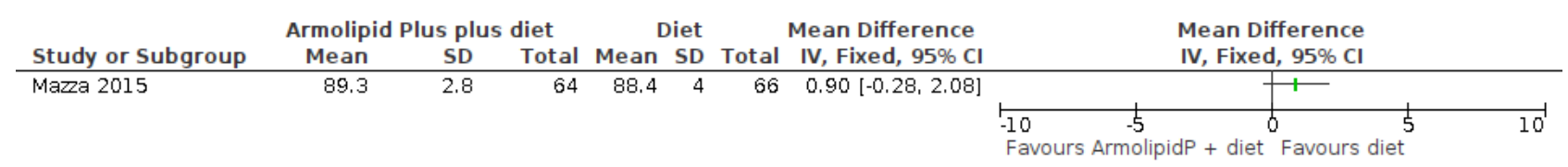

\section{Armolipid Prev versus placebo}

The study comparing Armolipid Prev to placebo [37] reported between-groups comparison of change from end of 2-week run-in to end of 6-week follow-up period, showing that experimental group SBP and DBP reduction was significantly higher compared to comparator group.

Effect estimates were calculated for SDB and DBP for both follow-up and change from 2-week run-in. For follow-up, effect estimates were -11.80 [-18.73, -4.87] mmHg for SBP (Figure 10), and -11.10 [-15.17, -7.43] mmHg for DBP (Figure 11), both statistically significant. For change from 2-week run-in, effect estimates were -16.00 [-22.40, -9.60] mmHg for SBP (Figure12), and -11.30 [-14.74, -7.46] mmHg for DBP (Figure 13), both statistically significant. 
Figure 10. Forest plot comparison: Armolipid Prev versus placebo; outcome: SBP at follow-up

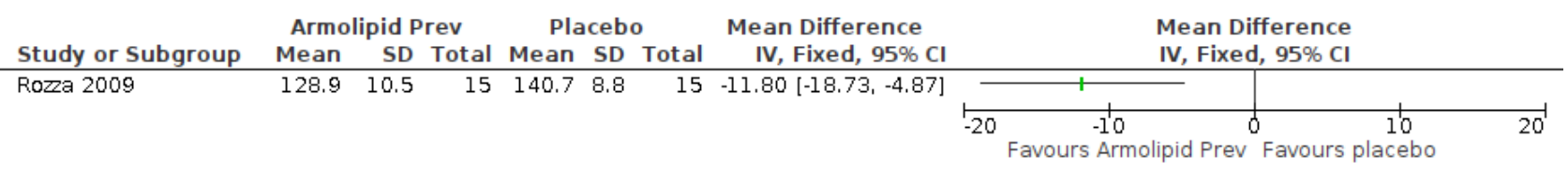

Figure 11. Forest plot comparison: Armolipid Prev versus placebo; outcome: DBP at follow-up

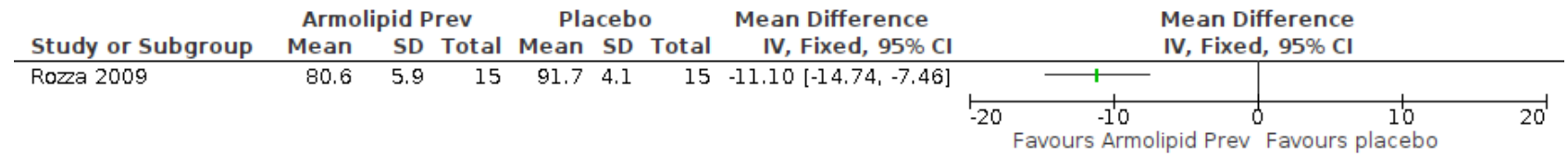

Figure 12. Forest plot comparison: Armolipid Prev versus placebo; outcome: SBP change from 2-week run-in to follow-up

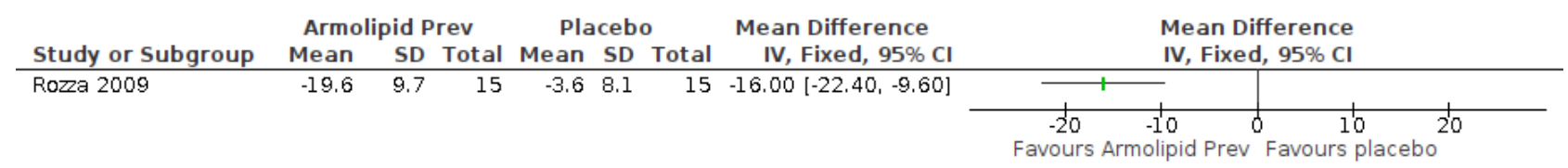

Figure 13. Forest plot comparison: Armolipid Prev versus placebo; outcome: DBP change from 2-week run-in to follow-up

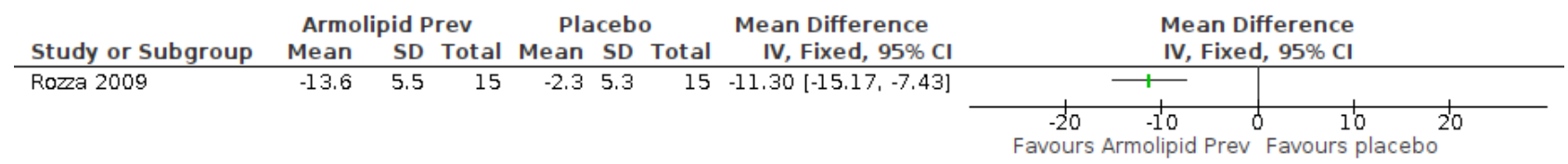

\section{Armolipid Prev versus Armolipid Plus}

The study comparing Armolipid Prev (experimental intervention) to Armolipid Plus (comparator intervention) did not report between-groups comparisons [38]. The study provided a significant $\mathrm{P}$ value for the comparison within experimental group between baseline and follow-up of both systolic and diastolic 24h-, daytime, and night-time ABPM. Comparison in comparator group were reported as not significant, with actual P values unreported. Effect estimates are given in Figure 14 to Figure 19, all below 4 mmHg in magnitude and not statistically significant.

The difference between the interventions was the presence in the experimental group of orthosiphon staminensi, which purported action as hypotensor was the object of the study investigation. Hence, 
this study alone does not provide insights on berberine effect, as both interventions contained equal doses of berberine. However, this study provides insights when combined to results of the study comparing Armolipid Prev to placebo [37]. Details are in the Discussion under Proprietary preparations containing berberine.

Figure 14. Forest plot comparison: Armolipid Prev versus Armolipid Plus; outcome: $24 \mathrm{~h}$ ambulatory SBP at follow-up

\begin{tabular}{lccccccccc} 
& \multicolumn{3}{c}{ Armolipid Prev } & \multicolumn{2}{c}{ Armolipid Plus } & \multicolumn{2}{c}{ Mean Difference } & \multicolumn{2}{c}{ Mean Difference } \\
IV, Fixed, 95\% CI
\end{tabular}

Figure 15. Forest plot comparison: Armolipid Prev versus Armolipid Plus; outcome: $24 \mathrm{~h}$ ambulatory DBP at follow-up

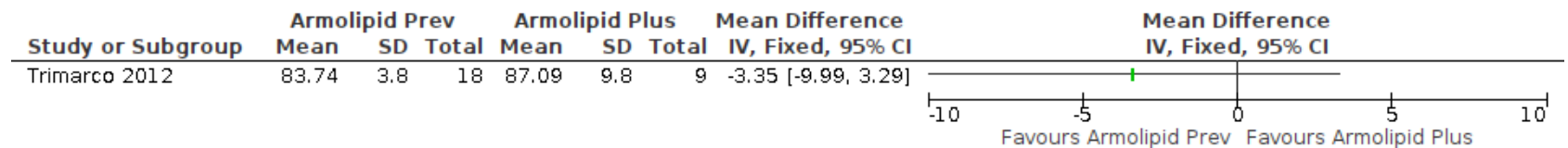

Figure 16. Forest plot comparison: Armolipid Prev versus Armolipid Plus; outcome: daytime ambulatory SBP at follow-up

\begin{tabular}{|c|c|c|c|c|c|c|c|c|c|c|}
\hline \multirow[b]{2}{*}{ Study or Subgroup } & \multicolumn{3}{|c|}{ Armolipid Prev } & \multicolumn{3}{|c|}{ Armolipid Plus } & \multirow{2}{*}{$\begin{array}{l}\text { Mean Difference } \\
\text { IV, Fixed, 95\% Cl }\end{array}$} & \multirow{2}{*}{\multicolumn{3}{|c|}{$\begin{array}{l}\text { Mean Difference } \\
\text { IV, Fixed, } 95 \% \mathrm{CI}\end{array}$}} \\
\hline & Mean & SD & Total & Mean & SD & Total & & & & \\
\hline Trimarco 2012 & 137.22 & 8.2 & 18 & 138.21 & 8.3 & 9 & $-0.99[-7.60,5.62]$ & +1 & & \\
\hline
\end{tabular}

Figure 17. Forest plot comparison: Armolipid Prev versus Armolipid Plus; outcome: daytime ambulatory DBP at follow-up

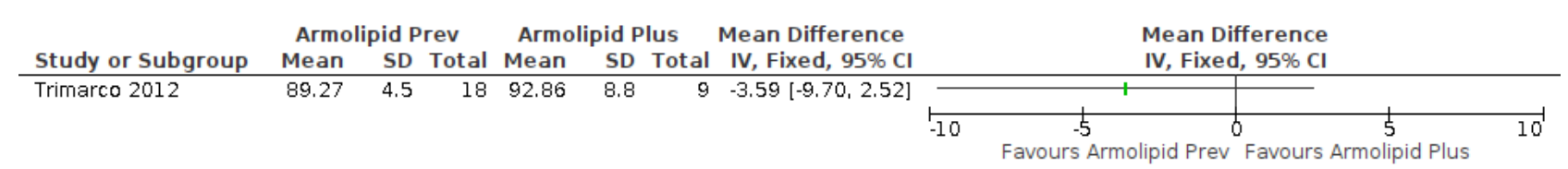

Figure 18. Forest plot comparison: Armolipid Prev versus Armolipid Plus; outcome: night-time ambulatory SBP at follow-up

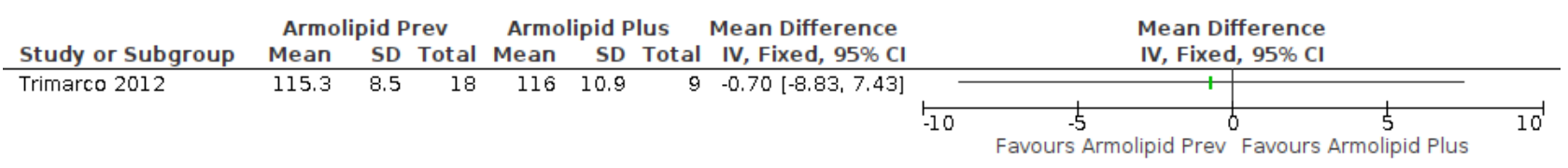


Figure 19. Forest plot comparison: Armolipid Prev versus Armolipid Plus; outcome: night-time ambulatory DBP at follow-up

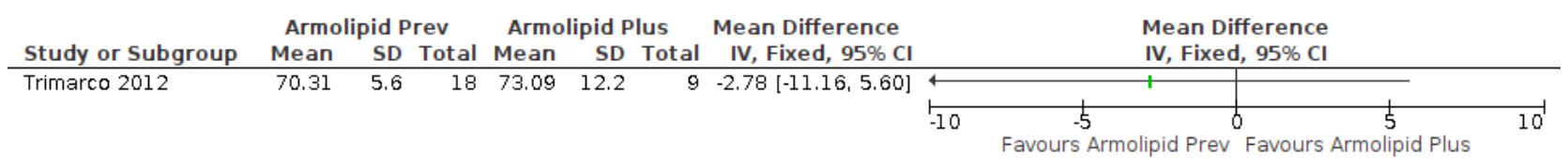

\subsubsection{Chunghyul-dan}

\section{Chunghyul-dan versus no intervention}

Two RCTs compared the herbal extract Chunghyul-dan to no intervention, one providing 72mg of berberine daily [36], the other 48mg [40]. In the first trial, experimental group SBP and DBP values were given at both baseline and follow-up [36]. These were reported as not significantly different. Effect estimates could not be calculated as comparator group follow-up SBP and DBP values were not given.

The second trial primary outcomes were systolic and diastolic 24h-ABPM [40]. Experimental group follow-up systolic value was reported as significantly lower than baseline. There was no significant difference between comparator group corresponding values. Diastolic values were not significantly different between baseline and follow-up within both groups. The study also reported that experimental group changes from baseline of systolic 24h-ABPM was significantly higher than in comparator group, but not of diastolic 24h-ABPM. Between-groups comparisons for follow-up values were not given. Effect estimates were calculated for both follow-up values and change from baseline for all outcomes. For follow-up, effects estimates were $-4.99[-11.81,1.83] \mathrm{mmHg}$ for both systolic 24h-ABPM, and 2.06 [-3.27, 7.39] mmHg for diastolic 24h-ABPM (Figure 20 and Figure 21), both not statistically significant. For change from baseline, effect estimates were -7.34 [-13.14, -1.54] mmHg (Figure 22) for systolic 24h-ABPM, statistically significant, and -0.70 [-5.28, 3.88] mmHg for diastolic 24h-ABPM (Figure 23), not significant. 
Figure 20. Forest plot comparison: Chunghyul-dan versus no intervention; outcome: $24 \mathrm{~h}$ ambulatory SBP at follow-up

\begin{tabular}{|c|c|c|c|c|c|c|c|c|c|c|c|}
\hline \multirow[b]{2}{*}{ Study or Subgroup } & \multicolumn{3}{|c|}{ Chunghyul-dan } & \multicolumn{3}{|c|}{ No intervention } & \multirow{2}{*}{$\begin{array}{l}\text { Mean Difference } \\
\text { IV, Fixed, } 95 \% \mathrm{Cl}\end{array}$} & \multirow{2}{*}{\multicolumn{4}{|c|}{$\begin{array}{l}\text { Mean Difference } \\
\text { IV, Fixed, 95\% CI }\end{array}$}} \\
\hline & Mean & SD & Total & Mean & SD & Total & & & & & \\
\hline Yun 2005 & 132.28 & 9.46 & 15 & 137.27 & 8.93 & 13 & $-4.99[-11.81,1.83]$ & & \begin{tabular}{l|l}
1 &
\end{tabular} & - & \\
\hline
\end{tabular}

Figure 21. Forest plot comparison: Chunghyul-dan versus no intervention; outcome: $24 \mathrm{~h}$ ambulatory DBP at follow-up

\begin{tabular}{|c|c|c|c|c|c|c|c|c|c|c|c|}
\hline \multirow[b]{2}{*}{ Study or Subgroup } & \multicolumn{3}{|c|}{ Chunghyul-dan } & \multicolumn{3}{|c|}{ No intervention } & \multirow{2}{*}{$\begin{array}{l}\text { Mean Difference } \\
\text { IV, Fixed, } 95 \% \mathrm{CI}\end{array}$} & \multirow{2}{*}{\multicolumn{4}{|c|}{$\begin{array}{l}\text { Mean Difference } \\
\text { IV, Fixed, } 95 \% \mathrm{Cl}\end{array}$}} \\
\hline & Mean & SD & Total & Mean & SD & Total & & & & & \\
\hline Yun 2005 & 83.06 & 8.03 & 15 & 81 & 6.34 & 13 & $2.06[-3.27,7.39]$ & & \begin{tabular}{l|l}
+1 \\
\end{tabular} & 1 & \\
\hline
\end{tabular}

Figure 22. Forest plot comparison: Chunghyul-dan versus no intervention; outcome: $24 \mathrm{~h}$ ambulatory SBP change from baseline to follow-up

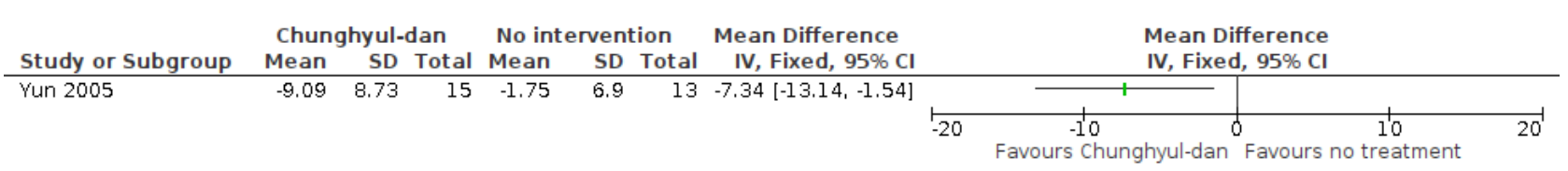

Figure 23. Forest plot comparison: Chunghyul-dan versus no intervention; outcome: $24 \mathrm{~h}$ ambulatory DBP change from baseline to follow-up

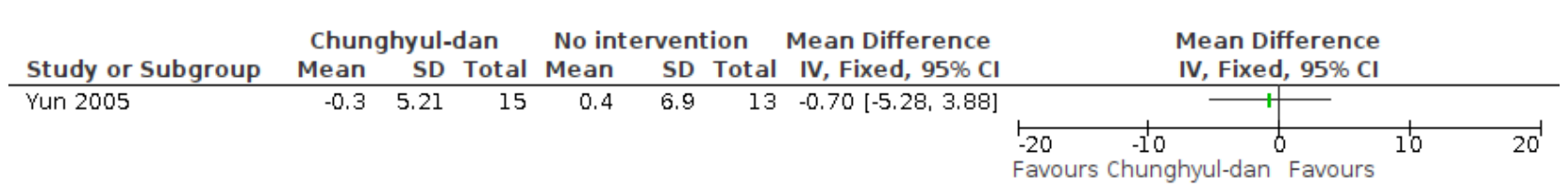

\section{Discussion}

\subsection{Summary of main results}

Even if literature reviews have suggested that berberine could be beneficial in hypertension, the evidence base presented here highlights a lack of high quality, long-term, high-powered controlled trials investigating berberine as hypertension treatment. Seven trials with 614 participants are included in this review. The mean duration of treatment was 2.6 months. Effect estimates were mixed, with most trials showing non-significant effects. Results from some trials were inconsistent. 
Trials demonstrated unclear or high risk of bias, due to missing details around randomisation and blinding, and to outcome reporting bias. Individual interventions are discussed below.

\subsubsection{Berberine as individual ingredient}

Compared with metformin, there was a significant moderate to large effect estimate in favour of berberine (1500mg daily) on SBP $(-11.87 \mathrm{mmHg})$. The study that compared the two regimens aimed at establishing berberine effect on insulin resistance in patients with type 2 diabetes [35]. Metformin own blood pressure effect cannot be excluded, and could lead to overestimate or underestimate berberine effect. However, an extended meta-analysis of 21 RCTs with 1667 patients with type 2 diabetes and hypertension showed that metformin did not significantly affect SBP or DBP [45]. Hence, the estimated effect is likely due to berberine alone. The trial comparing berberine (900mg daily) plus amlodipine to amlodipine only [33] did not show significant effect estimates.

The two studies had comparable group sizes, hence similar power of detecting effects. Lack of effect in the second study could have been due to the two experimental components interacting towards reducing effects. Or perhaps a dose effect was present; either $900 \mathrm{mg}$ of berberine daily had reduced effect compared to $1500 \mathrm{ng}$ daily, or 900mg was below berberine pharmacological action threshold, and 1500mg was above it. Another possibility is that, as the second study participants received also treatment for gout, the combination might have reduced effects.

\subsubsection{Proprietary preparations containing berberine}

The proprietary nutraceutical compound Armolipid Plus (berberine 500mg daily) in combination with diet was superior to diet alone [34]. The only statistically significant effect was on systolic 24h-ABPM, albeit small (-3.40 mmHg). Armolipid Plus contains additional ingredients, making it difficult to isolate berberine effect. The added ingredients are considered important in plasma lipids and glucose control, and not considered hypotensors [46]. However, Askarpour et al. [47] investigated policosanol effect on blood pressure. Their meta-analysis included 19 RCTs with 2426 participants with mainly hypercholesterolaemia, with hypertension present in two trials. They showed that an average of $12 \mathrm{mg}$ of policosanol daily, compared to placebo, significantly reduced SBP (-3.42 mmHg). As Armolipid Plus contains a comparable policosanol dose (10mg), the effect on systolic 24h-ABPM could be due to policosanol rather than berberine. Caution should be taken here as 24h-ABPM cannot immediately be compared against clinic SBP. 
Compared to placebo, Armolipid Prev (berberine 500mg daily) showed a significant moderate effect on SDB (-11.80 mmHg) and DBP (-11.10 mmHg). The effects on blood pressure were attributed to orthosiphon staminensi, the component added to Armolipid Plus to make Armolipid Prev [37]. However, in the study that compared Armolipid Prev against Armolipid Plus [38], effects on systolic and diastolic 24h-ABPM were not significant. Even if 24h-ABPM cannot immediately be compared against clinic SBP and DBP, the insights from these studies suggest an inconsistent effect from orthosiphon staminensi, leaving berberine and the other constituents as potential hypotensors.

\subsubsection{Chunghyul-dan}

Compared to no intervention, the effect of a 2-week intervention with the herbal extract Chunghyul-dan (berberine 48mg daily) estimated from the results of one study [40] was a significant moderate effect on systolic 24h-ABPM change from baseline (-7.34 mmHg). The effect estimates and precision from the other study providing $74 \mathrm{mg}$ of berberine daily from Chunghyul-dan and making a similar comparison over an 8-week intervention could not be calculated due to the lack of comparator group follow-up measures [36]. However, the study reported non significant changes within the experimental group.

These results seem inconsistent, as the second study showed no significant effect from a treatment dose $50 \%$ higher and a length of treatment four times longer than the trial showing a moderate effect. Also, the studies had comparable group sizes, hence both potentially able to discern similar effect. However, participants were selected from different populations. The study with favourable outcomes, with lower treatment dose and shorter intervention, recruited inpatients with hypertension admitted for stroke. The other study recruited outpatients with elevated baPWV and hypertension. Perhaps the effect was higher in the former because inpatients showed higher treatment adherence, possibly due to higher supervision and a more serious diagnosis (stroke) with actual symptoms, which might have increased participants' motivation to follow protocol. Moreover, the study with beneficial results had a 30\% drop-out rate, potentially introducing attrition bias. Also, its results are inconsistent with other included trials which for much higher berberine doses showed no significant effect. Hence, perhaps another constituent of Chunghyul-dan provided the hypotensive action. 


\subsection{Overall completeness and applicability of the evidence}

\subsubsection{Participants}

Participants' age and gender of the included trials were representative of patients with hypertension. Participants were selected in broadly similar proportions from Pakistan, Italy, and China, and to a lesser extent from Korea. This makes the evidence generally applicable to different populations and ethnicity.

All participants had hypertension. However, most trials excluded participants with severe hypertension, i.e., higher than $180 \mathrm{mmHg}$. Hence, the result of this review might not apply to this group of people. Also, all studies recruited participants who either had a hypertension diagnosis that occurred concomitantly with one another diagnosis, i.e., gout, hypercholesterolaemia, stroke, and low cardiovascular risk, or who did not necessarily have a formal diagnosis of hypertension but who had one other diagnosis, i.e., diabetes, metabolic syndrome, elevated baPWV, and who, at baseline assessment, resulted nonetheless to have hypertension. The results of this review might not apply to people affected only by hypertension.

\subsubsection{Interventions}

Only two studies investigated berberine as individual ingredient of known dose [33,35]. The other studies investigated berberine in combination with other therapeutic agents, making it problematic to isolate berberine contribution to effects.

The two studies investigating Chunghyul-dan failed to report the content of the individual active substances contained in their preparations [36,40], including berberine content, which for this review had to be estimated, with a unknown degree of imprecision, through a different study. However, this limitation might just reflect the stance that western medical research has in relation to treatment of diseases compared to the approach of Chinese and Ayurveda medicine. While the former often focuses on isolating the effect of individual therapeutic agents, the latter take the holistic approach of employing treatments made of whole and unrefined ingredients expected to act synergistically [48].

The length of interventions varied from two weeks to six months. The variation adds to the heterogeneity of the evidence. It also cannot shine any light on the effect of long-term use of berberine, both on intended and adverse outcomes. 


\subsubsection{Outcomes}

The primary goal of hypertension treatment is to prevent cardiovascular events. These were part of the primary outcomes of this review. The included trials did not report on cardiovascular event clinical endpoint, as all trials had a short-term follow-up. In any case, due to the relatively small sample sizes, these trials would have had little power to discriminate significant between-groups differences in the rate of the relatively rare cardiovascular events without a considerably long follow-up and increased costs.

Other outcomes from the included trials are primary outcomes of this review, namely, clinic SBP and DBP, and 24h-ABPM. However, blood pressure is a surrogate outcome. Temple defined the latter as "a laboratory measurement or a physical sign used as a substitute for a clinically meaningful endpoint that measures directly how a patient feels, functions or survives” [49]. In a major RCT, the large Antihypertensive and Lipid Lowering Treatment to Prevent Heart Attack Trial (ALLHAT) [50], doxazosin and chlorthalidone had comparable effects on blood pressure, but the risk of one of the clinical endpoint, namely, congestive heart failure, for patients on doxazosin was twice that of those on chlorthalidone. This suggested that some non-blood pressure related effect were present in one or both treatments in either direction. Hence, even if blood pressure is widely accepted as a reliable surrogate outcome for establishing the long-term cardiovascular benefit of hypotensors, inferring the effect of the latter on the basis of their action on blood pressure alone does not always adequately indicate what their effect would be on meaningful clinical endpoints. Measuring these endpoints is therefore key in understanding true efficacy of a drug, and certainly its long-term safety.

\subsubsection{Adverse outcomes}

The reporting of adverse events was inadequate. Only one study [36] measured several metabolic parameters and reported on statistical significance for their changes from baseline to follow-up. All other studies either did not report on safety, or at most mentioned that there were no adverse outcomes, or that interventions were safe. Studies were of short duration, hence no information can be drawn regarding long-term berberine undesired effects. The evidence from this review does not allow to establish the overall safety of berberine, albeit there is some indication that short term use is generally safe. 


\subsection{Quality of the evidence}

\subsubsection{Overall quality of studies}

All included trials were of low quality, in terms of design, reporting, and methodology. Two trials were not randomised, hence of intrinsically poorer quality in terms of allocation bias. All studies provided very limited or no description of design, randomisation, and allocation concealment. Baseline data was generally well reported, and intervention groups were similar within all trials. No study reported details on intention-to-treat analysis. Hence, all included trials were deemed to have unclear risk of allocation bias.

Most trials were designed or were likely to be designed as open-label, even when the addition of a placebo to the control arm could have been a viable option.

\subsubsection{Outcome reporting bias}

The overall body of evidence in this review shows a degree of outcome reporting bias, a problem often under-recognised by reviewers of RCTs [51]. No study used the CONSORT standards for reporting effect estimates [44]. Where the effect estimates calculated for this review showed, through comparison of between-groups outcomes, statistically significant beneficial effects of experimental interventions for some studies [34,35,37,40], those same studies but one [34] also reported the statistical significance of between-groups comparisons. Where, instead, the analyses showed not statistically significant effect estimates for the other studies [33,36,38], those studies did not report between-groups comparisons. They reported only on the statistical significance between baseline and follow-up value within groups, often showing significance for the experimental group. Hence, there seems to be an association between significance or non-significance of betweengroups comparisons and the reporting or not reporting of them, as shown in Table 2. Moreover, all studies reported statistically analyses only through $\mathrm{P}$ values, which inferiority have long ago be highlighted compared to the use of CIs [52].

Table 2. Outcome reporting bias analysis.

\begin{tabular}{lllll}
\hline Study ID & $\begin{array}{l}\text { Effect estimate statistically } \\
\text { significant }\end{array}$ & $\begin{array}{l}\text { Between-groups } \\
\text { statistical analyses } \\
\text { reported }\end{array}$ & $\begin{array}{l}\text { Within-group difference } \\
\text { between baseline and } \\
\text { follow-up values }\end{array}$ & $\begin{array}{l}\text { Within-group } \\
\text { statistical } \\
\text { analyses reported }\end{array}$ \\
\hline Huang 2013 & No & No & Significant for E and C & Yes \\
\hline
\end{tabular}




\begin{tabular}{|c|c|c|c|c|}
\hline Study ID & $\begin{array}{l}\text { Effect estimate statistically } \\
\text { significant }\end{array}$ & $\begin{array}{l}\text { Between-groups } \\
\text { statistical analyses } \\
\text { reported }\end{array}$ & $\begin{array}{l}\text { Within-group difference } \\
\text { between baseline and } \\
\text { follow-up values }\end{array}$ & $\begin{array}{l}\text { Within-group } \\
\text { statistical } \\
\text { analyses reported }\end{array}$ \\
\hline \multicolumn{5}{|l|}{ Huang 2013} \\
\hline \multicolumn{5}{|l|}{ [33] } \\
\hline Mazza 2015 & Yes for systolic 24h-ABPM & No & Significant for E & Yes \\
\hline [34] & No for diastolic 24h-ABPM & No & & \\
\hline Memon 2018 & Yes for SBP & Yes & Significant for E & Yes \\
\hline [35] & No for DBP & $\begin{array}{l}\text { Yes (wrongly states } \\
\text { significant) }\end{array}$ & & \\
\hline $\begin{array}{l}\text { Park } 2006 \\
\text { [36] }\end{array}$ & $\begin{array}{l}\text { Missing data for C did not } \\
\text { allow for analysis }\end{array}$ & No & $\begin{array}{l}\text { Not significant for E, no } \\
\text { data for } \mathrm{C}\end{array}$ & Yes \\
\hline \multirow[t]{2}{*}{$\begin{array}{l}\text { Rozza } 2009 \\
\text { [37] }\end{array}$} & $\begin{array}{l}\text { Yes for change from baseline } \\
\text { (larger effect estimate) }\end{array}$ & Yes & Significant for E & Yes \\
\hline & $\begin{array}{l}\text { Yes for follow-up (smaller } \\
\text { effect estimate) }\end{array}$ & No & & \\
\hline $\begin{array}{l}\text { Trimarco } 2012 \\
\text { [38] }\end{array}$ & No & No & Significant for E & Yes \\
\hline Yun 2005 [40] & $\begin{array}{l}\text { Yes for change from baseline } \\
\text { No for follow-up }\end{array}$ & $\begin{array}{l}\text { Yes } \\
\text { No }\end{array}$ & $\begin{array}{l}\text { Significant for E, not } \\
\text { significant for C }\end{array}$ & Yes \\
\hline
\end{tabular}

Note: E: Experimental group; C: Comparator group.

\subsection{Limitation and potential biases of the review process}

Chinese medical literature databases were not searched for this review. It is recognised that a review on a herbal medicine with a long history of use in China would warrant a search of Chinese databases. Indeed, the Chinese biomedical literature is large and growing, but often not available through databases in the English language. In their comparison between two systematic reviews answering the same question around diagnosing rheumatoid arthritis, one employing a search of databases in English and Chinese, the other searching only those in English, Cohen, Korevaar, Wang, Spijker, \& Bossuyt (2015) found that both reviews arrived at the same answer, with the same effect. However, the reviews compared were not on Chinese herbal medicine. Indeed, they still concluded that limiting systematic reviews to English only is common in systematic reviews and could result in biased effect estimates and reduce generalisability. 


\subsection{Agreements and disagreements with other reviews}

The search for this review revealed only one existing systematic review and meta-analysis on berberine for hypertension [18]. However, the study quality assessment and data pooling methods therein were found to be of low quality. Four papers in Chinese are included in the meta-analysis; the full-text was retrievable for one of them [33], translated, and included in this review; three papers were not retrievable (Zhong et al., 1997; Han et al., 1999; Sun et al., 2013; all cited in [19]).

In terms of quality assessment, in the meta-analysis the paper also included in this review [41] was given a Jadad score [54] of 4 (high quality). The Jadad score arrived at here was only 2 (low quality). This was based on randomisation being mentioned and described as random number tables, but double-blinding not being mentioned and attrition not being discussed. The study also resulted of poor quality through the SIGN tool used for this review. The authors of the metaanalysis did not mention having sought additional information from the author to justify a higher score. The other three studies were given a score of 2,3 , and 3 , respectively, hence of low to average quality.

For their meta-analysis, the authors pooled data from the two studies comparing amlodipine plus berberine versus amlodipine ([41]; Sun et al., 2013, cited in [19]). While it was not possible to retrieve Sun et al.'s paper, its data reported in [19] suggests that either Sun et al. conducted a study on a subgroup of the other study [41], or there was a data extraction error in the meta-analysis. If the first hypothesis is true, the meta-analysis has a unit-of-analysis error, which occurs when in a meta-analysis information from a treatment arm is used more than once [55]. Consequently, a significant effect estimate was obtained for both SBP and DBP from a single study that showed non-significant effects.

The same type of error occurred also in pooling the other two studies (Zhong et al., 1997; Han et al., 1999; all cited in [19]), the first comparing berberine to nitrendipine, the second with metropolol given at different doses in two comparator groups. Again, Han et al.'s experimental group is included twice in the same meta-analysis when pooling the comparisons with the two comparator groups. The correct approach would have been to first combine the two comparator groups results to arrive at one statistic, and then pool the data with the other study [56]. In this case, as Han et al.'s experiment favoured the comparator groups, effects were actually underestimated. Overall, the meta-analysis conclusion that berberine is effective in reducing blood pressure does not seem 
justifiable on the basis of the analyses it reports. Nonetheless, this work is widely cited to highlight berberine benefit. For example, in a narrative review on berberine for hypertension [57], berberine is reported as providing a significant benefit based on the said meta-analysis results. A similar conclusion is given in a review of berberine in metabolic syndrome [17].

\section{Conclusions}

\subsection{Implications for practice}

Hypertension is a condition affecting a large part of the world population, and widely accepted as a risk factor for developing cardiovascular disease. When lifestyle interventions fail to control blood pressure, drugs are offered to patients, who can be reluctant to take medications for an asymptomatic condition. Often patients turn to alternative therapies, perceived as safer and less prone to side effects. Berberine is one such therapy, having been used for millennia in Chinese and Ayurveda medicine, and in the last few years become more known in the western world.

This systematic review reveals that the evidence from clinical trials that investigated berberine effect on blood pressure, rate of cardiovascular events, and rate of adverse events, is of limited quantity and quality. The risk of bias of the limited number of relevant trials is high, especially around study design and reporting of outcomes. Some evidence points to varying degrees of beneficial effect of berberine at reducing blood pressure, albeit with inconsistencies across studies. The results did not demonstrate harm from the interventions, but caution needs to be taken before arriving at firm conclusions, as reporting of adverse events was limited, and no long-term data was available. Also, existing reviews have some flaws, and care is needed before using their results for clinical decision making.

Based solely on the evidence above, which comes in the form of Western medicine research methods, it cannot be suggested with a reasonable degree of confidence that berberine is effective or safe in the treatment of hypertension. However, this suggestion needs to be balanced with the extensive anecdotal evidence and the professional expertise originating from the ancient tradition of Eastern medicine, holding berberine as effective and safe hypertension treatment for a considerable fraction of the world population. 


\subsection{Implications for research}

This review includes only seven trial. Most trials' group size was small, duration was short, and related papers lacked details around trial design. Papers often omitted results on primary outcomes, or reported results without following widely accepted reporting standards.

A significant gap in the evidence is the lack of data around clinical endpoints, such as cardiovascular events. Adding these would increase the weight of the evidence, avoiding reliance on surrogate outcomes.

Given the methodological limitations demonstrated by the trials, there are some considerations for future trials. First, they should be adequately powered to allow for greater precision and estimate of long-term relatively rare events. Second, long-term follow-up should be considered to estimate clinically significant endpoints. And, finally, design and reporting of trials should follow the standards of the CONSORT statement. 


\section{References}

[1] G.W. Pickering, The natural history of hypertension., Br. Med. Bull. 8 (1952) 305-309. https://doi.org/10.1080/00325481.1963.11692902.

[2] N.R. Poulter, D. Prabhakaran, M. Caulfield, Hypertension, Lancet. 386 (2015) 801-812. https://doi.org/10.1016/S0140-6736(14)61468-9.

[3] National Institute for Health and Care Excellence, Hypertension in adults: Diagnosis and management (NG136), (2019). https://www.nice.org.uk/guidance/ng136 (accessed March 14, 2020).

[4] G. Mancia, G. De Backer, A. Dominiczak, R. Cifkova, R. Fagard, G. Germano, G. Grassi, A.M. Heagerty, S.E. Kjeldsen, S. Laurent, K. Narkiewicz, L. Ruilope, A. Rynkiewicz, R.E. Schmieder, H.A.J.S. Boudier, A. Zanchetti, 2007 Guidelines for the Management of Arterial Hypertension: The Task Force for the Management of Arterial Hypertension of the European Society of Hypertension (ESH) and of the European Society of Cardiology (ESC), J. Hypertens. 25 (2007) 1105-1187. https://doi.org/10.1097/HJH.0b013e3281fc975a.

[5] D. Ettehad, C.A. Emdin, A. Kiran, S.G. Anderson, T. Callender, J. Emberson, J. Chalmers, A. Rodgers, K. Rahimi, Blood pressure lowering for prevention of cardiovascular disease and death: A systematic review and meta-analysis, Lancet. 387 (2016) 957-967. https://doi.org/10.1016/S0140-6736(15)01225-8.

[6] National Centre for Social Research, Health Survey for England, 2018. [data collection], (2020). https://doi.org/http://doi.org/10.5255/UKDA-SN-8649-1.

[7] M. Aarabi, J. Skinner, C.E. Price, P.R. Jackson, Patients' acceptance of antihypertensive therapy to prevent cardiovascular disease: A comparison between South Asians and Caucasians in the United Kingdom, Eur. J. Prev. Cardiol. 15 (2008) 59-66. https://doi.org/10.1097/HJR.0b013e3282f07973.

[8] N. Nissen, S. Schunder-Tatzber, W. Weidenhammer, H. Johannessen, What attitudes and needs do citizens in Europe have in relation to complementary and alternative medicine?, Forsch. Komplementarmed. 19 (2012) 9-17. https://doi.org/10.1159/000342710.

[9] L.M. Kemppainen, T.T. Kemppainen, J.A. Reippainen, S.T. Salmenniemi, P.H. Vuolanto, Use of complementary and alternative medicine in Europe: Health-related and sociodemographic determinants, Scand. J. Public Health. 46 (2018) 448-455.

https://doi.org/10.1177/1403494817733869. 
[10] A. Kumar, Ekavali, K. Chopra, M. Mukherjee, R. Pottabathini, D.K. Dhull, Current knowledge and pharmacological profile of berberine: An update, Eur. J. Pharmacol. 761 (2015) 288-297. https://doi.org/10.1016/j.ejphar.2015.05.068.

[11] S. Kamath, M. Skeels, A. Pai, Significant differences in alkaloid content of Coptis chinensis (Huanglian), from its related American species, Chin. Med. 4 (2009) 17. https://doi.org/10.1186/1749-8546-4-17.

[12] A. Bagade, V. Tumbigeremutt, G. Pallavi, Cardiovascular Effects of Berberine: A Review of the Literature, J. Restor. Med. 6 (2017) 37-45. https://doi.org/10.14200/jrm.2017.6.0100.

[13] M. Imenshahidi, H. Hosseinzadeh, Berberine and barberry (Berberis vulgaris): A clinical review, Phyther. Res. 33 (2019) 504-523. https://doi.org/10.1002/ptr.6252.

[14] Z. Cai, C. Wang, W. Yang, Role of berberine in Alzheimer's disease, Neuropsychiatr. Dis. Treat. 12 (2016) 2509-2520. https://doi.org/10.2147/NDT.S114846.

[15] M. Zhang, L. Feng, J. Li, L. Chen, Therapeutic Potential and Mechanisms of Berberine in Cardiovascular Disease, Curr. Pharmacol. Reports. 2 (2016) 281-292. https://doi.org/10.1007/s40495-016-0070-1.

[16] N. Shinjyo, Parkinson, J. Bell, T. Katsuno, Berberine for prevention of dementia associated with diabetes and its comorbidities: A systematic review, J. Integr. Med. 18 (2020) 125-151. https://doi.org/http://dx.doi.org/10.1016/j.joim.2020.01.004.

[17] J. Tabeshpour, M. Imenshahidi, A review of the effects of berberis vulgaris and its major component, berberine, in metabolic syndrome, Iran. J. Basic Med. Sci. 20 (2017) 557-568. https://doi.org/http://dx.doi.org/10.22038/ijbms.2017.8682.

[18] J. Lan, Y. Zhao, F. Dong, Z. Yan, W. Zheng, J. Fan, G. Sun, L. J., Z. Y., D. F., Y. Z., Z. W., F. J., J. Lan, Y. Zhao, F. Dong, Z. Yan, W. Zheng, J. Fan, G. Sun, Meta-analysis of the effect and safety of berberine in the treatment of type 2 diabetes mellitus, hyperlipemia and hypertension., J. Ethnopharmacol. 161 (2015) 69-81.

https://doi.org/10.1016/j.jep.2014.09.049.

[19] W.S. Richardson, M.C. Wilson, J. Nishikawa, R.S. Hayward, The well-built clinical question: a key to evidence-based decisions, Am. Coll. Physicians J. Club. 123 (1995) A12-3. http://www.ncbi.nlm.nih.gov/entrez/query.fcgi? cmd=Retrieve $\& \mathrm{db}=$ PubMed\&dopt=Citation \&list_uids=7582737.

[20] J. Higgins, J. Thomas, J. Chandler, M. Cumpston, T. Li, M. Page, V. Welch, eds., 2.3 Defining the scope of a review question, in: Cochrane Handb. Syst. Rev. Interv. Version 6.0 (Updated July 2019), 2019. https://training.cochrane.org/handbook/current/chapter02\#section-2-3. 
[21] A. Liberati, D.G. Altman, J. Tetzlaff, C. Mulrow, P.C. Gøtzsche, J.P.A. Ioannidis, M. Clarke, P.J. Devereaux, J. Kleijnen, D. Moher, The PRISMA statement for reporting systematic reviews and meta-analyses of studies that evaluate health care interventions: Explanation and elaboration, PLoS Med. 6 (2009). https://doi.org/10.1371/journal.pmed.1000100.

[22] L. Shamseer, D. Moher, M. Clarke, D. Ghersi, A. Liberati, M. Petticrew, P. Shekelle, L.A. Stewart, D.G. Altman, A. Booth, A.W. Chan, S. Chang, T. Clifford, K. Dickersin, M. Egger, P.C. Gøtzsche, J.M. Grimshaw, T. Groves, M. Helfand, J. Higgins, T. Lasserson, J. Lau, K. Lohr, J. McGowan, C. Mulrow, M. Norton, M. Page, M. Sampson, H. Schünemann, I. Simera, W. Summerskill, J. Tetzlaff, T.A. Trikalinos, D. Tovey, L. Turner, E. Whitlock, Preferred reporting items for systematic review and meta-analysis protocols (prisma-p) 2015: Elaboration and explanation, BMJ. 349 (2015). https://doi.org/10.1136/bmj.g7647.

[23] National Institute for Health and Care Excellence, Developing NICE guidelines: the manual Appendix H Appraisal checklists, evidence tables, GRADE and economic profiles, 2018. https://www.nice.org.uk/process/pmg20/resources/appendix-h-pdf-2549710190.

[24] Medicines and Healthcare products Regulatory Agency, Yellow Card Scheme, (2020). https:// yellowcard.mhra.gov.uk/_assets/files/2015-10-29-HCP-leaflet.pdf (accessed July 29, 2020).

[25] F. Och, Statistical machine translation live, (2006) 1-2. https://ai.googleblog.com/2006/04/statistical-machine-translation-live.html (accessed June 4, 2020).

[26] J. Higgins, J. Thomas, J. Chandler, M. Cumpston, T. Li, M. Page, V. Welch, eds., 5.3 What data to collect, in: Cochrane Handb. Syst. Rev. Interv. Version 6.0 (Updated July 2019), 2019. https://training.cochrane.org/handbook/current/chapter-05\#section-5-3.

[27] Scottish Intercollegiate Guidelines Network, Methodology checklist 2: randomised controlled trials, (2020).

https://www.sign.ac.uk/media/1713/checklist_for_controlled_trials.doc (accessed July 29, 2020).

[28] Scottish Intercollegiate Guidelines Network, Methodology Checklist 2: Randomised Controlled Trials - Notes for completion of checklist, (2020).

https://www.sign.ac.uk/media/1717/notes_for_controlled_trials_checklist.doc (accessed July 29, 2020).

[29] B. Irvine, D.G. Green, M. Mckee, A. Dixon, E. Mossialos, A new system for grading recommendations in evidence based guidelines, Bmj. 325 (2002) 488.

https://doi.org/10.1136/bmj.325.7362.488.

[30] J. Sterne, J. Savović, M. Page, R. Elbers, N. Blencowe, I. Boutron, C. Cates, H.-Y. Cheng, M. Corbett, S. Eldridge, M. Hernán, S. Hopewell, A. Hróbjartsson, D. Junqueira, P. Jüni, J. Kirkham, T. Lasserson, T. Li, A. McAleenan, B. Reeves, S. Shepperd, I. Shrier, L. Stewart, 
K. Tilling, I. White, P. Whiting, J. Higgins, RoB 2: A revised Cochrane risk-of-bias tool for randomized trials, Bmj. (2019) 14898. https://methods.cochrane.org/.

[31] J. Higgins, J. Thomas, J. Chandler, M. Cumpston, T. Li, M. Page, V. Welch, eds., 6.1 Types of data and effect measures, in: Cochrane Handb. Syst. Rev. Interv. Version 6.0 (Updated July 2019), 2019. https://training.cochrane.org/handbook/current/chapter-06\#section-6-1.

[32] The Cochrane Collaboration, Review Manager (RevMan) [Computer program]. Version 5.4, (2020). https://training.cochrane.org/online-learning/core-software-cochrane-reviews/ revman/revman-5-download/download-and-installation.

[33] G. Huang, Effect of Amlodipine and Berberine in Mild and Midrange Hypertension Patients Complicated with Hyperuricemia Arthrolithiasis, China Pharm. 22 (2013) 32-33. http://en.cnki.com.cn/Article_en/CJFDTotal-YYGZ201305019.htm.

[34] A. Mazza, S. Lenti, L. Schiavon, M. Zuin, M. D’Avino, E. Ramazzina, E. Casiglia, Nutraceuticals for Serum Lipid and Blood Pressure Control in Hypertensive and Hypercholesterolemic Subjects at Low Cardiovascular Risk, Adv. Ther. 32 (2015) 680-690. https://doi.org/http://dx.doi.org/10.1007/s12325-015-0229-X.

[35] M. Memon, R. Khan, S. Riaz, Q. Ain, M. Ahmed, N. Kumar, Methylglyoxal and insulin resistance in berberine-treated type 2 diabetic patients, J. Res. Med. Sci. 23 (2018). https://doi.org/10.4103/jrms.JRMS_1078_17.

[36] S.U. Park, W.S. Jung, S.K. Moon, C.N. Ko, K.H. Cho, Y.S. Kim, H.S. Bae, Chunghyul-Dan (Qingxue-Dan) Improves Arterial Stiffness in Patients with Increased baPWV, Am. J. Chin. Med. 34 (2006) 553 563. https://doi.org/10.1142/S0192415X06004090.

[37] F. Rozza, G. De Simone, R. Izzo, N. De Luca, B. Trimarco, Nutraceuticals for treatment of high blood pressure values in patients with metabolic syndrome, High Blood Press. Cardiovasc. Prev. 16 (2009) 177-182. https://doi.org/http://dx.doi.org/10.2165/11530420000000000-00000.

[38] V. Trimarco, C.S. Cimmino, M. Santoro, G. Pagnano, M.V. Manzi, A. Piglia, C.A. Giudice, N. De Luca, R. Izzo, Nutraceuticals for Blood Pressure Control in Patients with High-Normal or Grade 1 Hypertension, 19 (2012) 117-122. https://login.ezproxy.napier.ac.uk/login? url=https://search.ebscohost.com/login.aspx? direct $=$ true $\& \mathrm{db}=$ cmedm\&AN=22994579\&site=ehost-live.

[39] V. Trimarco, R. Izzo, A. Vasta, R. Giudice, C.S. Cimmino, F. Rozza, S. Crispo, A. Piglia, N. Ragosa, S. Damiano, N. De Luca, A new approach for treatment of patients with high-normal blood pressure, High Blood Press. Cardiovasc. Prev. 18 (2011) 151. https://doi.org/http://dx.doi.org/10.2165/11593530-000000000-00000.

[40] S.P. Yun, W.S. Jung, S.U. Park, S.K. Moon, C.N. Ko, K.H. Cho, Y.S. Kim, H.S. Bae, Antihypertensive effect of Chunghyul-dan (Qingxue-dan) on stroke patients with essential 
hypertension, Am. J. Chin. Med. 33 (2005) 357-364.

https://doi.org/http://dx.doi.org/10.1142/S0192415X05002977.

[41] D. Moher, A. Liberati, J. Tetzlaff, D.G. Altman, D. Altman, G. Antes, D. Atkins, V. Barbour, N. Barrowman, J.A. Berlin, J. Clark, M. Clarke, D. Cook, R. D’Amico, J.J. Deeks, P.J. Devereaux, K. Dickersin, M. Egger, E. Ernst, P.C. Gøtzsche, J. Grimshaw, G. Guyatt, J. Higgins, J.P.A. Ioannidis, J. Kleijnen, T. Lang, N. Magrini, D. McNamee, L. Moja, C. Mulrow, M. Napoli, A. Oxman, B. Pham, D. Rennie, M. Sampson, K.F. Schulz, P.G. Shekelle, D. Tovey, P. Tugwell, Preferred reporting items for systematic reviews and metaanalyses: The PRISMA statement, PLoS Med. 6 (2009).

https://doi.org/10.1371/journal.pmed.1000097.

[42] W. Chung, J. Ryu, S. Chung, S. Kim, Effect of Qingxue Dan on obesity and metabolic biomarker: a double-blind randomized-controlled pilot study, J. Tradit. Chin. Med. 36 (2016) 291-298. https://doi.org/10.1016/s0254-6272(16)30040-1.

[43] L.A. McGuinness, J.P.T. Higgins, Risk of bias VISualization (robvis): An R package and Shiny web app for visualizing risk of bias assessments, Res. Synth. Methods. (2020) 1-7. https://doi.org/10.1002/jrsm.1411.

[44] D. Moher, S. Hopewell, K.F. Schulz, V. Montori, P.C. Gøtzsche, P.J. Devereaux, D. Elbourne, M. Egger, D.G. Altman, CONSORT 2010 explanation and elaboration: Updated guidelines for reporting parallel group randomised trials, Int. J. Surg. 10 (2012) 28-55. https://doi.org/10.1016/j.ijsu.2011.10.001.

[45] M.G. Wulffelé, A. Kooy, D. De Zeeuw, C.D.A. Stehouwer, R.T. Gansevoort, The effect of metformin on blood pressure, plasma cholesterol and triglycerides in type 2 diabetes mellitus: A systematic review, J. Intern. Med. 256 (2004) 1-14. https://doi.org/10.1111/j.1365-2796.2004.01328.x.

[46] M. Pirro, M.R. Mannarino, V. Bianconi, L.E. Simental-Mendía, F. Bagaglia, E. Mannarino, A. Sahebkar, The effects of a nutraceutical combination on plasma lipids and glucose: A systematic review and meta-analysis of randomized controlled trials, Pharmacol. Res. 110 (2016) 76-88. https://doi.org/10.1016/j.phrs.2016.04.021.

[47] M. Askarpour, E. Ghaedi, N. Roshanravan, A. Hadi, H. Mohammadi, M.E. Symonds, M. Miraghajani, Policosanol supplementation significantly improves blood pressure among adults: A systematic review and meta-analysis of randomized controlled trials, Complement. Ther. Med. 45 (2019) 89-97. https://doi.org/10.1016/j.ctim.2019.05.023.

[48] Y. Sun, K. Xun, Y. Wang, X. Chen, A systematic review of the anticancer properties of berberine, a natural product from Chinese herbs, Anticancer. Drugs. 20 (2009) 757-769. https://doi.org/10.1097/CAD.0b013e328330d95b. 
[49] K. Gupta, J. Gupta, S. Singh, “Can You Handle the Truth?” Surrogate Endpoints: How Reliable Are They?, 2010. www.firstclinical.com (accessed July 23, 2020).

[50] J. D’Agostino, Debate: The slippery slope of surrogate outcomes, Curr. Control. Trials Cardiovasc. Med. 1 (2000) 76-78. https://doi.org/10.1186/CVM-1-2-076.

[51] J.J. Kirkham, K.M. Dwan, D.G. Altman, C. Gamble, S. Dodd, R. Smyth, P.R. Williamson, The impact of outcome reporting bias in randomised controlled trials on a cohort of systematic reviews, BMJ. 340 (2010) 637-640. https://doi.org/10.1136/bmj.c365.

[52] J.N.S. Matthews, D.G. Altman, Statistics Notes: Interaction 2: Compare effect sizes not P values, BMJ. 313 (1996) 808. https://doi.org/10.1136/bmj.313.7060.808.

[53] J.F. Cohen, D.A. Korevaar, J. Wang, R. Spijker, P.M. Bossuyt, Should we search Chinese biomedical databases when performing systematic reviews?, Syst. Rev. 4 (2015) 1-5. https:// doi.org/10.1186/s13643-015-0017-3.

[54] A.R. Jadad, R.A. Moore, D. Carroll, C. Jenkinson, D.J.M. Reynolds, D.J. Gavaghan, H.J. McQuay, Assessing the quality of reports of randomized clinical trials: Is blinding necessary?, Control. Clin. Trials. 17 (1996) 1-12. https://doi.org/10.1016/01972456(95)00134-4.

[55] J. Higgins, J. Thomas, J. Chandler, M. Cumpston, T. Li, M. Page, V. Welch, eds., 6.2 Study designs and identifying the unit of analysis, in: Cochrane Handb. Syst. Rev. Interv. Version 6.0 (Updated July 2019), 2019. https://training.cochrane.org/handbook/current/chapter06\#section-6-2.

[56] J. Higgins, J. Thomas, J. Chandler, M. Cumpston, T. Li, M. Page, V. Welch, eds., 23.3.4 How to include multiple groups from one study, in: Cochrane Handb. Syst. Rev. Interv. Version 6.0 (Updated July 2019), 2019. https://raining.cochrane.org/handbook/current/chapter23\#section-23-3-4.

[57] S.G. Chrysant, G.S. Chrysant, Herbs Used for the Treatment of Hypertension and their Mechanism of Action, Curr. Hypertens. Rep. 19 (2017) 1-10. https://doi.org/10.1007/s11906017-0775-5.

[58] J.I. Cleeman, Executive summary of the third report of the National Cholesterol Education Program (NCEP) expert panel on detection, evaluation, and treatment of high blood cholesterol in adults (adult treatment panel III), J. Am. Med. Assoc. 285 (2001) 2486-2497.

https://doi.org/10.1001/jama.285.19.2486. 


\section{Appendix 1 - Characteristics of included studies}

\section{Huang 2013}

\begin{tabular}{|c|c|}
\hline Method & Randomised controlled trial. Randomisation method not specified. \\
\hline Study setting & Lishui City Central Hospital, Zhejiang Province, China. \\
\hline \multirow[t]{12}{*}{ Participants } & $\begin{array}{l}\mathrm{N}=164 \text {, randomised: } \mathrm{E}=84, \mathrm{C}=80 \text {. Loss to follow-up not discussed in the } \\
\text { paper. }\end{array}$ \\
\hline & Patients admitted to hospital from January 2010 to January 2011. \\
\hline & Inclusion criteria: mild to moderate hypertension (diagnostic criteria not \\
\hline & specified), and gout (BUA for males not less than $420 \mu \mathrm{mol} / \mathrm{L}$, for female not \\
\hline & less than $360 \mu \mathrm{mol} / \mathrm{L})$. \\
\hline & Exclusion criteria: endocrine or renal diseases, severe hypertension, history \\
\hline & of cardiovascular and cerebrovascular accidents within 6 months, severe \\
\hline & heart, liver, and kidney dysfunction, drug allergies. \\
\hline & Among the 164 patients, 98 were male and 66 were female; aged 42-74 \\
\hline & years, with an average age of $(61.1 \pm 2.8)$ years. \\
\hline & No significant differences between groups at baseline for BUA, SBP, and \\
\hline & DBP, and all other measured parameters. \\
\hline \multirow[t]{6}{*}{ Interventions } & $\begin{array}{l}\text { E: oral berberine hydrochloride } 300 \mathrm{mg} \text { three times a day in addition to C } \\
\text { group intervention. }\end{array}$ \\
\hline & C: oral amlodipine tablets (Zhejiang Hongyuan Pharmaceutical Chemical \\
\hline & Co., Ltd.) $5 \mathrm{mg}$ twice a day, oral colchicine $1 \mathrm{mg}$ three times a day if patients \\
\hline & with acute gout, or oral allopurinol $50 \mathrm{mg}$ twice a day if patients had chronic \\
\hline & 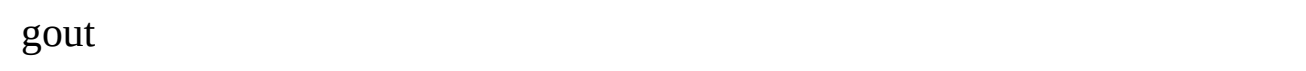 \\
\hline & Both intervention lasted 8 weeks. \\
\hline \multirow[t]{2}{*}{ Outcomes } & Within both groups, follow up SBP and DBP were significantly lower than \\
\hline & baseline values $(\mathrm{E}: 127.6 \pm 12.5 \mathrm{mmHg}$ vs $155.8 \pm 18.2 \mathrm{mmHg} \mathrm{p}<0.05,81.5$ \\
\hline
\end{tabular}


$\pm 10.7 \mathrm{mmHg}$ vs $99.1 \pm 5.4 \mathrm{mmHg} \mathrm{p}<0.05$; C: $132.1 \pm 18.31 \mathrm{mmHg}$ vs 157.3

$\pm 22.8 \mathrm{mmHg} \mathrm{p}<0.05,83.5 \pm 5.2 \mathrm{mmHg}$ vs $99.5 \pm 6.1 \mathrm{mmHg} \mathrm{p}<0.05)$.

However, the between groups comparison of follow-up SBP and DBP

showed no statistically significant differences. Author does mention this in

the result section, but in the conclusion only the statistically significant

difference between baseline and follow-up within the E group is highlighted.

It was not possible to compare changes from baseline between groups as this were not reported in the paper.

Adverse events: not discussed. Author mentions that intervention was safe.

\begin{tabular}{ll}
$\begin{array}{l}\text { Publication } \\
\text { details }\end{array}$ & Study in Chinese. \\
\hline Notes & $\begin{array}{l}\text { E: Experimental group, C: Comparator group, BUA: Blood Uric Acid, SBP: } \\
\text { systolic blood pressure, DBP: diastolic blood pressure. }\end{array}$ \\
\hline
\end{tabular}

\section{Study quality assessment}

\begin{tabular}{|c|c|c|}
\hline Question & $\begin{array}{l}\text { Author's } \\
\text { answer }\end{array}$ & Support for answer \\
\hline $\begin{array}{l}\text { 1. The study addresses an } \\
\text { appropriate and clearly focused } \\
\text { question (reporting bias) }\end{array}$ & Yes & $\begin{array}{l}\text { The study specifies that the aim was to } \\
\text { investigate the effect on hypertension of } \\
\text { amlodipine combined with berberine. }\end{array}$ \\
\hline $\begin{array}{l}\text { 2. The assignment of subjects to } \\
\text { treatment groups is randomised } \\
\text { (allocation bias) }\end{array}$ & Can’t say & $\begin{array}{l}\text { Insufficient information available to } \\
\text { permit a judgement. }\end{array}$ \\
\hline $\begin{array}{l}\text { 3. An adequate concealment method } \\
\text { is used (allocation bias). }\end{array}$ & Can’t say & $\begin{array}{l}\text { Insufficient information available to } \\
\text { permit a judgement. }\end{array}$ \\
\hline $\begin{array}{l}\text { 4. The design keeps subjects and } \\
\text { investigators 'blind' about } \\
\text { treatment allocation (performance } \\
\text { bias, detection bias) }\end{array}$ & No & $\begin{array}{l}\text { No placebo is given to comparator } \\
\text { group, likely to be open label study. }\end{array}$ \\
\hline
\end{tabular}


5. The treatment and control groups

No statistically significant differences at are similar at the start of the trial baseline between groups in respect to (allocation bias) gender, age, BUA, SBP, and DBP.

6. The only difference between Yes No other interventions are mentioned. groups is the treatment under investigation (performance bias)

7. All relevant outcomes are Can’t say Insufficient information available to measured in a standard, valid and permit a judgement. reliable way (detection bias)

8. The drop out rate is acceptable Can’t say Insufficient information available to (attrition bias) permit a judgement.

9. All the subjects are analysed in Can’t say Insufficient information available to the groups to which they were permit a judgement. randomly allocated (attrition bias)

\section{Mazza 2015}

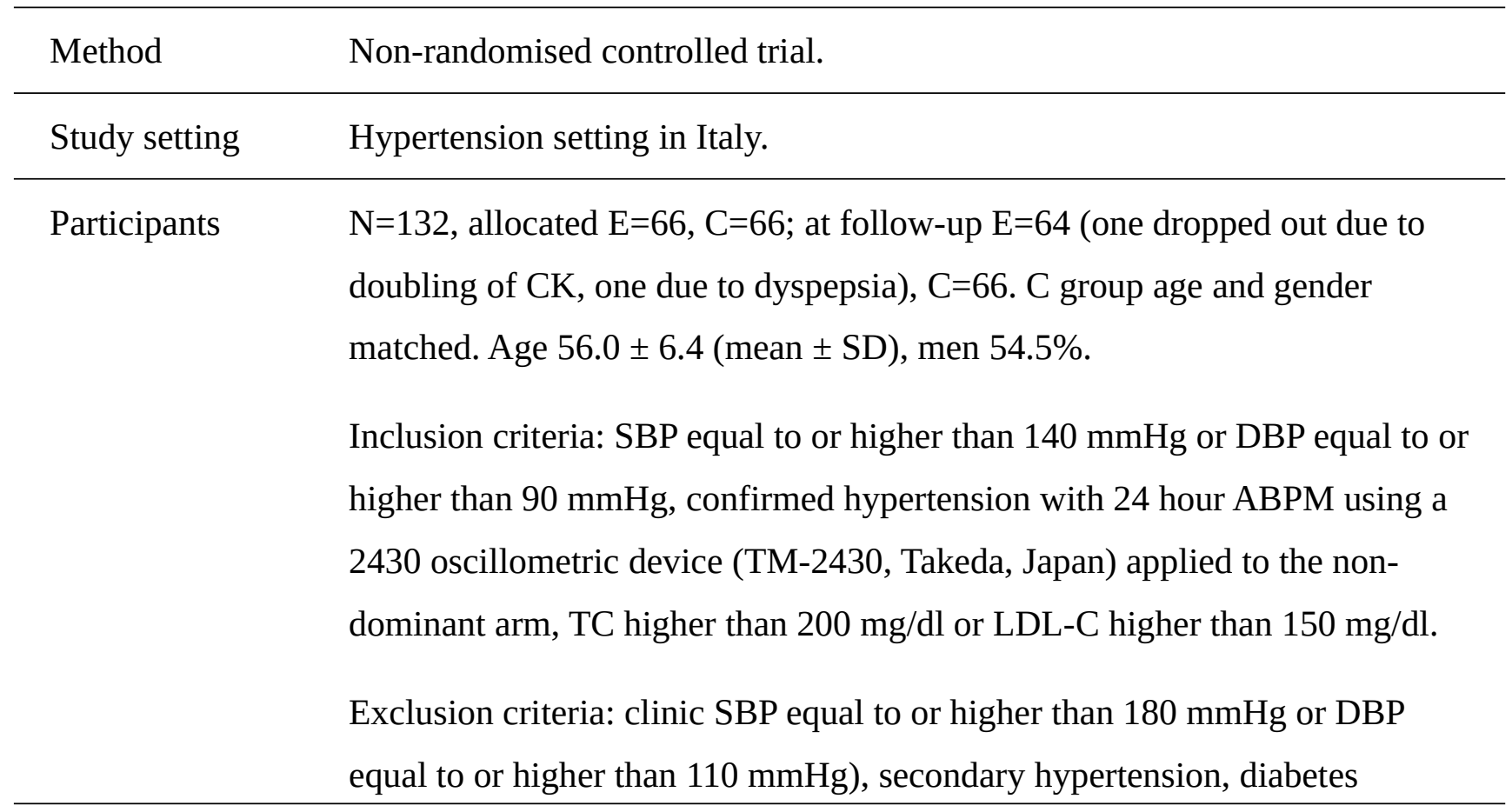


mellitus, presence of neoplastic or hepatic disease, chronic heart or renal failure, positive history or clinical signs of ischemic heart disease, severe obesity (BMI equal to or higher than $35 \mathrm{~kg} / \mathrm{m}^{2)}$, disabling diseases such as dementia or inability to cooperate, pregnancy or breastfeeding, antihypertensive and/or lipid-lowering drug treatment, and organ damage (left ventricular hypertrophy diagnosed by electrocardiogram, carotid plaque or albuminuria) due to hypertension.

No significant differences between groups at baseline for SBP, and DBP. Only PP (SBP-DBP) was significantly higher in E group. All other measures differences were not statistically significant.

Interventions E: Armolipid Plus (Rottapharm SpA, a MEDA Company), one tablet, once daily in the evening before bedtime, for 6 months, in addition to a specific dietary regimen as in group $\mathrm{C}$.

C: written prescription for a standardised Mediterranean diet regimen, including a high intake of fish, fruits, vegetables, legumes, olive oil, unrefined whole grains and a moderate intake of lean meats and alcohol.

Note: ArmoLipid Plus is a food supplement combining natural ingredients containing red yeast rice (equivalent of $3 \mathrm{mg}$ of monacolin $\mathrm{K}$ ), $10 \mathrm{mg}$ of policosanol, $500 \mathrm{mg}$ of berberine, $0.2 \mathrm{mg}$ of folic acid, $0.5 \mathrm{mg}$ of astaxanthin and 2 mg of coenzyme Q10.

2-week run in period when baseline values were taken. Then 6-months intervention.

Outcomes SBP, DBP. systolic and diastolic day 24h, night 24h, 24h ABPM.

For E group, of all blood pressure measures, only the change from baseline of 24h ABPM measurements was statistically significant: (141.6 $\pm 6.4 \mathrm{mmHg}$ at baseline vs. $136.2 \pm 4.8 \mathrm{mmHg}$ at follow-up; $\mathrm{p}<0.05$ ).

For $\mathrm{C}$ group, all the difference measures pre- and post-intervention were not statistically significant. Post-intervention values for $\mathrm{C}$ group are not given in 
the paper, only bar charts are shown, from which precise numerical value cannot be extracted.

No comparison between groups given in the study. It was not possible to compare post-intervention outcomes between groups, or compare changes from baseline between groups due to the lack of reporting of outcome measures in $\mathrm{C}$ group.

High risk of reporting bias.

Adverse events: two participants in E withdrawn from the study due to side effects (one due to a doubling in CK levels and one due to dyspepsia). Otherwise, all safety parameters measured had no significant changes among E and C.

\begin{tabular}{ll}
\hline $\begin{array}{l}\text { Publication } \\
\text { details }\end{array}$ & $\begin{array}{l}\text { Study in English. Article processing charges for this study were funded by } \\
\text { Rottapharm SpA, a MEDA Company, Monza, Italy, manufacturer of the } \\
\text { tested nutraceutical compound. }\end{array}$ \\
\hline Notes & E: experimental group, C: comparator group, SBP: systolic blood pressure, \\
DBP: diastolic blood pressure, PP: pulse pressure, BMI: body mass index, \\
ABPM: ambulatory blood pressure monitoring, TC: total cholesterol, LDL- \\
C: low-density lipoprotein cholesterol, CK: creatinine kinase.
\end{tabular}

Study quality assessment

\begin{tabular}{|c|c|c|}
\hline Question & $\begin{array}{l}\text { Author's } \\
\text { answer }\end{array}$ & Support for answer \\
\hline $\begin{array}{l}\text { 1. The study addresses an } \\
\text { appropriate and clearly focused } \\
\text { question (reporting bias) }\end{array}$ & Yes & $\begin{array}{l}\text { The aim was clearly stated as } \\
\text { investigating the effect of nutraceuticals } \\
\text { on serum lipid and blood pressure } \\
\text { control in hypertensive and } \\
\text { hypercholesterolaemic subjects. }\end{array}$ \\
\hline $\begin{array}{l}\text { 2. The assignment of subjects to } \\
\text { treatment groups is randomised }\end{array}$ & No & $\begin{array}{l}\text { Non-randomised controlled trial. Age } \\
\text { and gender matched comparator group. }\end{array}$ \\
\hline
\end{tabular}


(allocation bias)

3. An adequate concealment method No Non-randomised controlled trial. is used (allocation bias).

4. The design keeps subjects and Non Non-randomised controlled trial. investigators ‘blind’ about treatment allocation (performance bias, detection bias)

5. The treatment and control groups Yes No significant differences between are similar at the start of the trial (allocation bias) groups at baseline for SBP, and DBP. Only PP (SBP-DBP) was significantly higher in E group. All other measures differences were not statistically significamt.

6. The only difference between Yes No other interventions are mentioned. groups is the treatment under investigation (performance bias)

7. All relevant outcomes are measured in a standard, valid and reliable way (detection bias)

8. The drop out rate is acceptable (attrition bias)

9. All the subjects are analysed in the groups to which they were randomly allocated (attrition bias)
Yes

All blood pressures measure techniques are described in details, and reflect standard accepted practice.

Yes Two participants withdrew from E group.

Can’t say Insufficient information available to permit a judgement.

\section{Memon 2018}




\begin{tabular}{|c|c|}
\hline Study setting & $\begin{array}{l}\text { Tertiary care hospital, Department of Medicine, Liaquat University of } \\
\text { Medical and Health Sciences, Jamshoro/Hyderabad, Pakistan, from March } \\
2016 \text { to January } 2017 \text {. }\end{array}$ \\
\hline Participants & $\begin{array}{l}\mathrm{N}=200, \mathrm{E}=100, \mathrm{C}=100 \text {. C group age and gender matched. No loss to follow- } \\
\text { up. } \\
\text { Inclusion criteria: subjects with newly diagnosed type } 2 \text { DM cases of age } \\
\geq 25 \text { years taking drug metformin. } \\
\text { Exclusion criteria: subjects with type } 2 \mathrm{DM} \text { taking sulfonylurea, herbal } \\
\text { drugs, HMG-CoA reductase inhibitors, and multivitamin pills and insulin, } \\
\text { subjects with type } 2 \text { DM with diabetic complications, and subjects with type } \\
2 \text { DM with concomitant chronic viral hepatic disorders, coronary ischemic } \\
\text { heart disease, chronic kidney disease, and pregnancy. } \\
\text { No significant differences for most measured parameters. LDL-C and HDL- } \\
\text { C levels where significantly different. Age E: } 33.4 \pm 2.96 y e a r s, ~ C: ~ 33.26 \pm \\
2.6 y e a r s, ~ p=0.81 \text {; body weight E: } 64.37 \pm 11.6 \mathrm{~kg}, \mathrm{C}: 60.8 \pm 8.95 \mathrm{~kg}, \mathrm{p}=0.09 \text {; } \\
\text { LDL-C E: } 109.2 \pm 16.4 \mathrm{mg} / \mathrm{dl}, \mathrm{C}: 181.9 \pm 43.07 \mathrm{mg} / \mathrm{dl}, \mathrm{p}=0.0001 \text {; HDL-C E: } \\
\text { 33.65 } \pm 11.36 \mathrm{mg} / \mathrm{dl} \text {, C: } 34.5 \pm 0.47 \mathrm{mg} / \mathrm{dl}, \mathrm{p}=0.04 \text {. }\end{array}$ \\
\hline Interventions & $\begin{array}{l}\text { E: berberine } 500 \text { mg three times a day. } \\
\text { C: metformin (Glucophage, Merck Pharmaceuticals) } 500 \text { mg three times a } \\
\text { day. } \\
\text { Intervention lasted for } 3 \text { months. }\end{array}$ \\
\hline Outcomes & $\begin{array}{l}\text { SBP and DBP were not stated main outcomes in the study. However, } \\
\text { measures are reported for pre- and post-intervention for both groups. The } \\
\text { authors also carried out between groups comparison. Paper reports that, at } \\
\text { follow-up, both SBP and DBP were significantly lower than those in C group } \\
\text { (but see note below): } 131.4 \pm 15.2 \mathrm{mmHg} \text { vs } 143.3 \pm 19.0 \mathrm{mmHg} \mathrm{p}=0.001 \text {, } \\
70.61 \pm 13.65 \mathrm{mmHg} \text { vs } 72.57 \pm 11.2 \mathrm{mmHg} \mathrm{p}=0.03 \text {. } \\
\text { It was not possible to compare changes from baseline between groups. }\end{array}$ \\
\hline
\end{tabular}


Adverse events not discussed in the paper.

Note: DBP difference at $\mathrm{f} / \mathrm{u}$ is NS. Calculated significant level $\mathrm{p}=0.27$, not $\mathrm{p}=0.03$ as paper reports.

\begin{tabular}{ll}
\hline $\begin{array}{l}\text { Publication } \\
\text { details }\end{array}$ & Study in English. \\
\hline Notes & E: experimental group, C: comparator group, SBP: systolic blood pressure, \\
& DBP: diastolic blood pressure, DM: diabetes mellitus.
\end{tabular}

\section{Study quality assessment}

\begin{tabular}{|c|c|c|}
\hline Question & $\begin{array}{l}\text { Author's } \\
\text { answer }\end{array}$ & Support for answer \\
\hline $\begin{array}{l}\text { 1. The study addresses an } \\
\text { appropriate and clearly focused } \\
\text { question (reporting bias) }\end{array}$ & Yes & $\begin{array}{l}\text { The aim was clearly stated as } \\
\text { determining the effects of berberine } \\
\text { therapy on serum methylglyoxal and } \\
\text { insulin resistance in newly diagnosed } \\
\text { type } 2 \text { diabetic patients. }\end{array}$ \\
\hline $\begin{array}{l}\text { 2. The assignment of subjects to } \\
\text { treatment groups is randomised } \\
\text { (allocation bias) }\end{array}$ & No & $\begin{array}{l}\text { Non-randomised controlled trial. Age } \\
\text { and gender matched comparator group. }\end{array}$ \\
\hline $\begin{array}{l}\text { 3. An adequate concealment method } \\
\text { is used (allocation bias). }\end{array}$ & No & Non-randomised controlled trial. \\
\hline $\begin{array}{l}\text { 4. The design keeps subjects and } \\
\text { investigators 'blind' about } \\
\text { treatment allocation (performance } \\
\text { bias, detection bias) }\end{array}$ & No & Non-randomised controlled trial. \\
\hline $\begin{array}{l}\text { 5. The treatment and control groups } \\
\text { are similar at the start of the trial } \\
\text { (allocation bias) }\end{array}$ & Yes & $\begin{array}{l}\text { No significant differences for most } \\
\text { measured parameters. Body weight } \\
\text { and cholesterol levels where } \\
\text { significantly different. }\end{array}$ \\
\hline
\end{tabular}


6. The only difference between groups is the treatment under investigation (performance bias)

7. All relevant outcomes are Can’t say Insufficient information available to measured in a standard, valid and permit a judgement. reliable way (detection bias)

8. The drop out rate is acceptable Yes No loss to follow-up. (attrition bias)

9. All the subjects are analysed in Can't say Insufficient information available to the groups to which they were permit a judgement. randomly allocated (attrition bias)

\section{Park 2006}

\begin{tabular}{ll}
\hline Method & Randomised controlled trial. \\
\hline Study setting & $\begin{array}{l}\text { Outpatients visiting the Cardiovascular Center of Kyung Hee University } \\
\text { Kangnam Korean Hospital between November } 2003 \text { and October } 2004 .\end{array}$ \\
\hline Participants & N=35, E=20, C=15. Loss to follow-up not described. \\
& $\begin{array}{l}\text { Exclusion criteria: baPWV higher than } 1400 \mathrm{~cm} / \mathrm{sec} . \\
\text { to the study, use of anti-hyperlipidemic agents or steroids within } 6 \text { months, } \\
\text { or the presence of hepatic or renal diseases. } \\
\text { No statistically significant differences between groups at baseline in terms of } \\
\text { age, gender, SBP, DBP, and baPWV. Age E: } 61.4 \pm 9.6 y e a r s, \text { C: } 63.4 \pm \\
\text { 10.5year p=0.644; gender (male vs female) E: } 6 \text { vs } 14 \text {, C: } 4 \text { vs } 11 \text { p=0.863 }\end{array}$ \\
\hline E: CHD 600mg three times a day. For this review, the content of berberine is \\
\hline Interventions
\end{tabular}


calculated as $4 \%$ of total preparation using estimate in [58]. Hence, total estimated berberine daily dose was $24 \mathrm{mg}$ three times a day.

C: Observations only.

Interventions lasted for 8 weeks.

Outcomes SBP and DBP were not primary outcomes of the study, baPWV was the main outcome. For E group SBP and DBP are given at baseline (152.9 \pm 22.0 $\mathrm{mmHg}$ and $91.3 \pm 8.0 \mathrm{mmHg})$ and follow-up (137.6 $\pm 13.3 \mathrm{mmHg}$ and 87.2 $\pm 8.2 \mathrm{mmHg}$ ), and the differences were not statistically significant. For $\mathrm{C}$ group only baseline SBP and DBP values are given in the paper. This represent a high risk of reporting bias.

Between-groups comparisons of SBP and DBP were not given in the paper.

Because of the lack of reporting of SBP and DBP values for C group at follow-up, for this review it was not possible to calculate between-groups comparison of post-intervention values of SBP and DBP or comparison of changes from baseline.

While baPWV was not an outcome of interest for this review, it is worth noting that values for baPWV are given at baseline and follow-up for both groups. The paper highlights that, in E group, follow-up value was significant lower than baseline, but not for C group. However, for this review, between-groups comparison of follow-up values were calculated, and showed no statistically significant difference. As this was not an outcome of interest of this review, the actual calculations are not reported.

There were no clinical adverse effects observed during the 8 weeks of treatment. There were no statistically significant changes in E group pre- and post-intervention values for the following monitored parameters: AST, ALT, BUN, and CR.

Publication Study in English.

details 
Notes

E: experimental group, C: comparator group, SBP: systolic blood pressure, DBP: diastolic blood pressure, baPWV: brachial-ankle pulse wave velocity, CHD: chunghyul-dan, AST: aspatate transaminase, ALT: alanine transaminase, BUN: blood urea nitrogen, CR: creatinine

\section{Study quality assessment}

\begin{tabular}{|c|c|c|}
\hline Question & $\begin{array}{l}\text { Author's } \\
\text { answer }\end{array}$ & Support for answer \\
\hline $\begin{array}{l}\text { 1. The study addresses an } \\
\text { appropriate and clearly focused } \\
\text { question (reporting bias) }\end{array}$ & Yes & $\begin{array}{l}\text { Aim of the study was the effect of } \\
\text { Chunghyul-dan (CHD) (Qingxue- } \\
\text { Dan) on arterial stiffness in patients } \\
\text { with raised baPWV. }\end{array}$ \\
\hline $\begin{array}{l}\text { 2. The assignment of subjects to } \\
\text { treatment groups is randomised } \\
\text { (allocation bias) }\end{array}$ & Can’t say & $\begin{array}{l}\text { Insufficient information available to } \\
\text { permit a judgement. }\end{array}$ \\
\hline $\begin{array}{l}\text { 3. An adequate concealment method } \\
\text { is used (allocation bias). }\end{array}$ & Can’t say & $\begin{array}{l}\text { Insufficient information available to } \\
\text { permit a judgement. }\end{array}$ \\
\hline $\begin{array}{l}\text { 4. The design keeps subjects and } \\
\text { investigators 'blind' about } \\
\text { treatment allocation (performance } \\
\text { bias, detection bias) }\end{array}$ & No & $\begin{array}{l}\text { Blinding not mentioned. There was no } \\
\text { placebo in comparator group. Very } \\
\text { likely to be open label study. }\end{array}$ \\
\hline $\begin{array}{l}\text { 5. The treatment and control groups } \\
\text { are similar at the start of the trial } \\
\text { (allocation bias) }\end{array}$ & Yes & $\begin{array}{l}\text { Participants similar in all measured } \\
\text { parameters: age, gender, SBP, DBP, } \\
\text { baPWV, }\end{array}$ \\
\hline $\begin{array}{l}\text { 6. The only difference between } \\
\text { groups is the treatment under } \\
\text { investigation (performance bias) }\end{array}$ & Yes & Yes, no other intervention is described. \\
\hline $\begin{array}{l}\text { 7. All relevant outcomes are } \\
\text { measured in a standard, valid and }\end{array}$ & Can’t say & $\begin{array}{l}\text { SBP, DBP, and baPWV said to be } \\
\text { measured per usual way as measured at }\end{array}$ \\
\hline
\end{tabular}


reliable way (detection bias)

8. The drop out rate is acceptable (attrition bias)

9. All the subjects are analysed in the groups to which they were randomly allocated (attrition bias) the trial hospital.

Can’t say Insufficient information available to permit a judgement.

Can’t say Insufficient information available to permit a judgement.

\section{Rozza 2009}

\begin{tabular}{ll}
\hline Method & Randomised controlled trial. \\
\hline Study setting & Italy. No other details given in the paper. \\
\hline Participants & N=30, E=15, C=15. No loss to follow-up. \\
& Inclusion criteria: subjects of both sexes aged 18-75 years and with a \\
& diagnosis of metabolic syndrome established according to the NCEP ATP-III \\
& criteria [17], i.e., subjects with at least subjects with at least three of these \\
& factors: waist measurement higher than 102cm for men and higher than \\
& 88cm for women, fasting glycaemia equal to or higher than 100mg/dL, \\
& arterial blood pressure equal to or higher than 130/85mmHg, trigliceride \\
& equal to or higher than 150mg/dL; HDL-C less than 40mg/dL for men or \\
& less than 50mg/dL for women. \\
& Exclusion criteria: subjects who were pregnant or breastfeeding women and \\
& patients treated with antihypertensive and/or lipid-lowering drugs. \\
& At baseline there were no statistically significant differences between all \\
measured parameters, including age, gender, SBP, and DBP. Age E: $47.5 \pm$ \\
10.1years, C: 45.5 \pm 10.8years, NS; sex (M/F\%) E: 67/33; C: 73.3/26.7. \\
folic acid and coenzyme Q10 with the addition of Orthosiphon Staminensi \\
\hline Interventions
\end{tabular}


(Armolipid Prev, Rottapharm, Monza, Italy). The paper does not specify actual content in mg of the individual components of Armolipid Prev.

However, Armolipid Prev is made up of Armolipid Plus with the addition of Orthosiphon Staminensi. Armolipid Plus content is given in the included study by Mazza et al. (2015) as red yeast rice (equivalent of $3 \mathrm{mg}$ of monacolin K), $10 \mathrm{mg}$ of policosanol, $500 \mathrm{mg}$ of berberine, $0.2 \mathrm{mg}$ of folic acid, $0.5 \mathrm{mg}$ of astaxanthin and $2 \mathrm{mg}$ of coenzyme Q10.

C: placebo.

There was a 2-week run-in period when both groups received dietary advice and placebo. Then the interventions as above run for 6 weeks.

Outcomes SDB and DBP were part of the primary outcomes measures. Measures are given in the paper at baseline, after 2-week run-in period, and at 6-week folllow-up. The authors did a between group comparison of change from 2week run-in to 6-week follow-up, showing that E group had, compared to C group, a significant higher SBP reduction (-19.6 \pm 9.7 vs $-3.6 \pm 8.1 \mathrm{mmHg}$; $\mathrm{p}<0.0001)$ and DBP reduction $(-13.6 \pm 5.5$ vs $-2.3 \pm 5.3 \mathrm{mmHg} ; \mathrm{p}<0.0001)$. Between groups comparison of follow-up values were made for this review. The paper reports no adverse outcomes, but does not give details.

Publication Study in English.

details

Notes

E: experimental group, C: comparator group, SBP: systolic blood pressure, DBP: diastolic blood pressure, HDL-C: high density lipoprotein cholesterol, NS: non-significant.

Study quality assessment

\begin{tabular}{lll}
\hline Question & $\begin{array}{l}\text { Author's } \\
\text { answer }\end{array}$ & Support for answer \\
\hline $\begin{array}{lll}\text { 1. The study addresses an } \\
\text { appropriate and clearly focused }\end{array}$ & Yes & $\begin{array}{l}\text { There was clear focus on investigating } \\
\text { reduction of blood pressure in patients }\end{array}$ \\
\hline
\end{tabular}


question (reporting bias)

with metabolic syndrome treated with nutraceuticals.

2. The assignment of subjects to Can’t say Insufficient information available to treatment groups is randomised permit a judgement. (allocation bias)

3. An adequate concealment method Can’t say Insufficient information available to is used (allocation bias). permit a judgement.

4. The design keeps subjects and Can’t say Double-blinding mentioned. Insufficient investigators 'blind' about information available to permit a treatment allocation (performance judgement. bias, detection bias)

5. The treatment and control groups Yes At baseline there were no statistically are similar at the start of the trial significant differences between all (allocation bias) measured parameters, including age, gender, SBP, and DBP.

6. The only difference between Yes Yes, no other intervention is described. groups is the treatment under investigation (performance bias)

7. All relevant outcomes are Yes Systolic and diastolic blood pressure measured in a standard, valid and reliable way (detection bias) were measured by standard sphygmomanometer after 5 minutes in the supine position, according to the guidelines of the European Society of Cardiology and the European Society of Hypertension [4]. Three blood pressure measurements were obtained in the sitting position at 2-minute intervals. The averages of these measurements were used for the analysis. 

8. The drop out rate is acceptable
Yes
No loss to follow-up. (attrition bias)
9. All the subjects are analysed in Can’t say Insufficient information available to the groups to which they were permit a judgement. randomly allocated (attrition bias)

\section{Trimarco 2012}

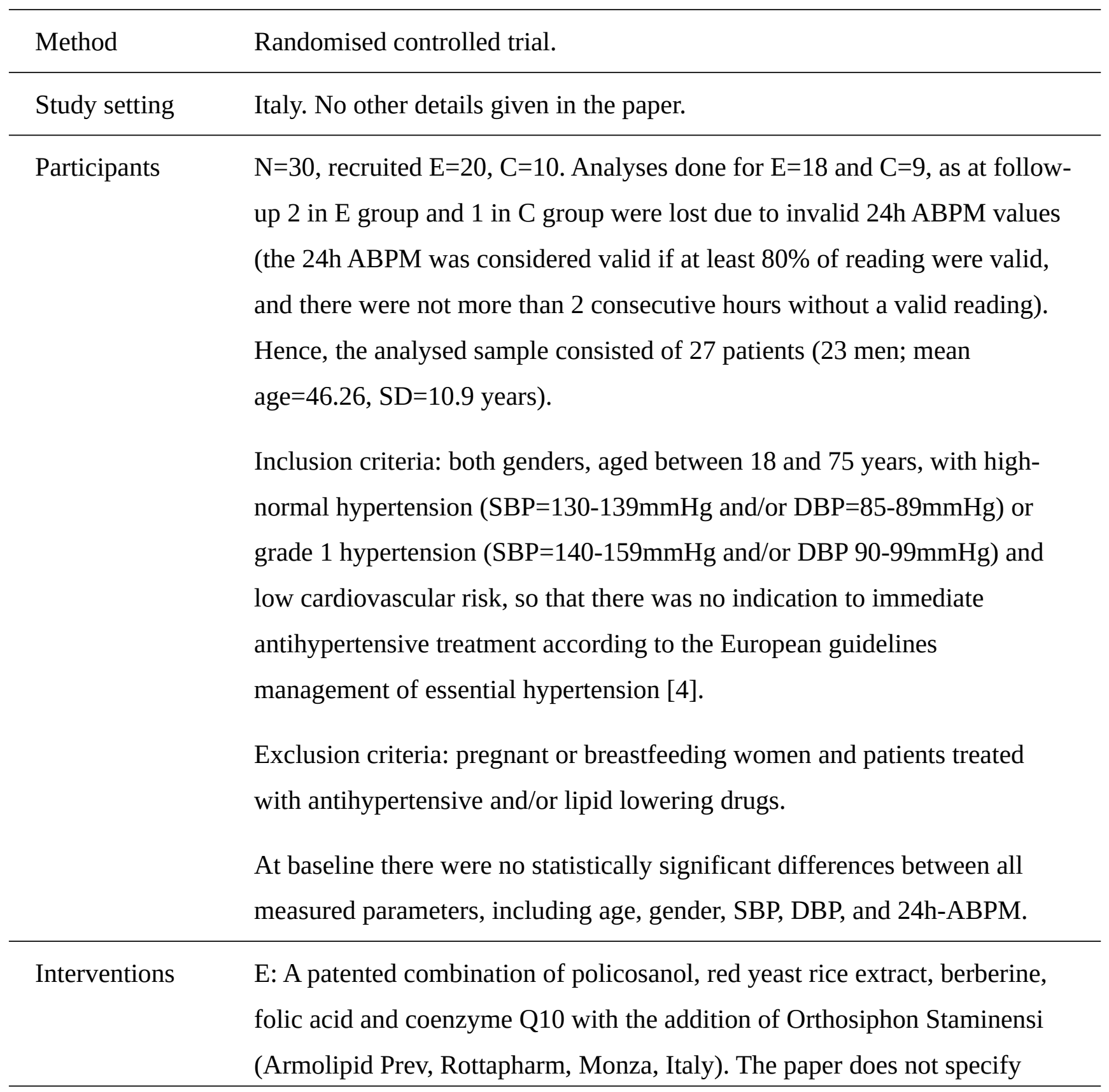


actual content in mg of the individual components of Armolipid Prev.

However, Armolipid Prev is made up of Armolipid Plus with the addition of Orthosiphon Staminensi. Armolipid Plus content is given in the included study by Mazza et al. (2015) as red yeast rice (equivalent of $3 \mathrm{mg}$ of monacolin K), $10 \mathrm{mg}$ of policosanol, $500 \mathrm{mg}$ of berberine, $0.2 \mathrm{mg}$ of folic acid, $0.5 \mathrm{mg}$ of astaxanthin and $2 \mathrm{mg}$ of coenzyme Q10.

C: Armolipid Plus.

There was a 2-week run-in period when both groups received dietary advice and placebo. Then the interventions as above run for 4 weeks.

Outcomes 24h-ABPM, daytime ABPM, and night-time ABPM were the primary outcome measures. In E group, at 4-week follow-up all measures had significant reduction from baseline, for both systolic and diastolic. 24hABPM: $130.98 \pm 7.2$ vs $135.87 \pm 8.2 \mathrm{mmHg} ; \mathrm{p}=0.0001 ; 83.74 \pm 3.8$ vs $87.34 \pm 4.4 \mathrm{mmHg}, \mathrm{p}=0.0001$; daytime: $137.22 \pm 8.2$ vs $141.82 \pm 8.1 \mathrm{mmHg}$, $\mathrm{p}=0.002$, $89.27 \pm 4.5$ vs $92.83 \pm 4.4 \mathrm{mmHg}, \mathrm{p}=0.001$; night-time: $115.30 \pm$ 8.5 vs $121.46 \pm 10.8 \mathrm{mmHg}, \mathrm{p}=0.008,70.31 \pm 5.6$ vs $74.01 \pm 7.5 \mathrm{mmHg}, \mathrm{p}=$ 0.037. In C group, measures at baseline and at 4-week follow-up were not significantly different.

No between groups comparisons are given in the paper. Between groups comparison of values at follow-up were carried out for this review. It was not possible to do between groups comparison of changes from baseline.

Adverse outcomes: authors state that there was a lack of adverse reactions. No other details are given.

Publication Study in English.

details

Notes

E: experimental group, C: comparator group, SBP: systolic blood pressure, DBP: diastolic blood pressure, ABPM: ambulatory blood pressure monitoring. 


\section{Study quality assessment}

\begin{tabular}{lll}
\hline Question & $\begin{array}{l}\text { Author's } \\
\text { answer }\end{array}$ & Support for answer \\
\hline $\begin{array}{l}\text { 1. The study addresses an } \\
\text { appropriate and clearly focused }\end{array}$ & Yes & $\begin{array}{l}\text { There was clear focus on investigating } \\
\text { reduction of blood pressure in patients } \\
\text { question (reporting bias) }\end{array}$ \\
$\begin{array}{lll}\text { 2. The assignment of subjects to } \\
\text { treatment groups is randomised } \\
\text { (allocation bias) }\end{array}$ & Can't say & nutraceutical. \\
\hline
\end{tabular}

3. An adequate concealment method Can’t say Insufficient information available to is used (allocation bias). permit a judgement.

4. The design keeps subjects and No Blinding not mentioned. investigators 'blind' about treatment allocation (performance bias, detection bias)

5. The treatment and control groups Yes are similar at the start of the trial (allocation bias)
At baseline there were no statistically significant differences between all measured parameters, including age, gender, SBP, DBP, and 24h-ABPM.

6. The only difference between Yes $\quad$ Yes, no other intervention is described. groups is the treatment under investigation (performance bias)

7. All relevant outcomes are measured in a standard, valid and reliable way (detection bias)
Yes
ABPM devices (Spacelabs model 90207, Rendmond, WA, USA) were used with the appropriately sized cuff and bladder. The units were programmed to take measurements at 15-minute intervals during the day and 
the evening (8:00am to $11: 00 \mathrm{pm})$ and at 20-minute intervals during the night (11:00pm to 8:00am) throughout the 24hour period. With this device, the first BP measurement appears on the device's display screen, but all subsequent measures are blinded.
8. The drop out rate is acceptable
Yes At follow-up 2 in E group and 1 in C (attrition bias) group were lost due to invalid 24h ABPM values.

9. All the subjects are analysed in Can’t say Insufficient information available to the groups to which they were permit a judgement. randomly allocated (attrition bias)

\section{Yun 2005}

\begin{tabular}{|c|c|}
\hline Method & Randomised controlled trial. \\
\hline Study setting & $\begin{array}{l}\text { Department of Cardiovascular and Neurologic Diseases (Stroke Center), } \\
\text { Hospital of Oriental Medicine, Kyung Hee Medical Center, Seoul, Korea, } \\
\text { from } 1 \text { June } 2003 \text { to } 31 \text { March } 2004 .\end{array}$ \\
\hline Participants & $\begin{array}{l}\mathrm{N}=40 \text {, recruited } \mathrm{E}=20, \mathrm{C}=20 \text {. At follow-up } \mathrm{E}=15, \mathrm{C}=13 \text {. From } \mathrm{C} \text { group } 5 \\
\text { subjects dropped out due to unexpected early discharge and } 2 \text { due to data } \\
\text { errors; from } \mathrm{E} \text { group } 3 \text { subjects dropped out due to unexpected early } \\
\text { discharge and } 2 \text { due to data errors. The final analysis was performed on the } \\
\text { remaining } 28 \text {. }\end{array}$ \\
\hline & $\begin{array}{l}\text { Inclusion criteria: subjects hospitalised } 10 \text { days after stroke with stage } 1 \\
\text { hypertension defined in the seventh report of the Joint National Committee } \\
\text { on Prevention, Detection, Evaluation, and Treatment of High Blood }\end{array}$ \\
\hline
\end{tabular}


Pressure, i.e., sitting SBP between 140-159 mmHg or DBP between 90-99 mmHg. White coat hypertension was excluded (SBP below $125 \mathrm{mmHg}$ or DBP below $80 \mathrm{mmHg}$ ) by 2 . The diagnosis of stroke was made when neurologic4h-ABPM. The diagnosis of stroke was made when neurological deficits were accompanied by corresponding abnormal computed tomography or magnetic resonance imaging findings of the brain.

Exclusion criteria: subjects who were taking hypotensors, who had hepatic or renal diseases, or experienced cardiovascular disease within three months.

At baseline there were no statistically significant differences between all measured parameters, including age, gender, 24h-ABPMSBP, and DBP.

Interventions $\quad$ E: Chunghyul-dan (Qingxue-dan) 1200mg once a day. For this review, the content of berberine is calculated as $4 \%$ of total preparation using estimate in (Chung, Ryu, Chung, \& Kim, 2016). Hence, total estimated berberine daily dose was $48 m g$ once a day.

C: No intervention.

Intervention lasted for 2 weeks.

Outcomes Systolic and diastolic 24h-ABPM were part of the primary outcomes. Preinterventions, post-interventions, and change from baseline values are given in the paper for both groups.

E group change from baseline of systolic 24h-ABPM, from $141.37 \pm 8.96$ $\mathrm{mmHg}$ to $132.28 \pm 9.46 \mathrm{mmHg}(\mathrm{P}=0.03)$, was statistically significant, as was the corresponding mean change from baseline of $9.09 \pm 8.73 \mathrm{mmHg}$.

No other between-groups comparison are not given in the paper. These were calculated for this review, for both follow-up and change from baseline.

Adverse outcomes: authors report that no adverse effect was found, and 5 subjects showed improvement of symptoms (two insomnia, one constipation, and one pruritus).

Publication Study in English. 
details

Notes

E: experimental group, C: comparator group, SBP: systolic blood pressure, DBP: diastolic blood pressure, ABPM: ambulatory blood pressure monitoring.

\section{Study quality assessment}

\begin{tabular}{|c|c|c|}
\hline Question & $\begin{array}{l}\text { Author’s } \\
\text { answer }\end{array}$ & Support for answer \\
\hline $\begin{array}{l}\text { 1. The study addresses an } \\
\text { appropriate and clearly focused } \\
\text { question (reporting bias) }\end{array}$ & Yes & $\begin{array}{l}\text { There was clear focus on investigating } \\
\text { the effect of Chunghyul-dan } \\
\text { (Qingxue-dan) on blood pressure in } \\
\text { hospitalised patients just diagnosed } \\
\text { with stroke and hypertension. }\end{array}$ \\
\hline $\begin{array}{l}\text { 2. The assignment of subjects to } \\
\text { treatment groups is randomised } \\
\text { (allocation bias) }\end{array}$ & Can’t say & $\begin{array}{l}\text { Insufficient information available to } \\
\text { permit a judgement. }\end{array}$ \\
\hline $\begin{array}{l}\text { 3. An adequate concealment method } \\
\text { is used (allocation bias). }\end{array}$ & Can’t say & $\begin{array}{l}\text { Insufficient information available to } \\
\text { permit a judgement. }\end{array}$ \\
\hline $\begin{array}{l}\text { 4. The design keeps subjects and } \\
\text { investigators 'blind' about } \\
\text { treatment allocation (performance } \\
\text { bias, detection bias) }\end{array}$ & No & $\begin{array}{l}\text { Authors mention in the paper that } \\
\text { placebo was not used, as it was } \\
\text { impossible to provide a placebo of same } \\
\text { smell, colour, taste and weight as the } \\
\text { experimental intervention. }\end{array}$ \\
\hline $\begin{array}{l}\text { 5. The treatment and control groups } \\
\text { are similar at the start of the trial } \\
\text { (allocation bias) }\end{array}$ & Yes & $\begin{array}{l}\text { At baseline there were no statistically } \\
\text { significant differences between all } \\
\text { measured parameters, including age, } \\
\text { gender, 24h-ABPMSBP, and DBP. }\end{array}$ \\
\hline $\begin{array}{l}\text { 6. The only difference between } \\
\text { groups is the treatment under }\end{array}$ & Yes & Yes, no other intervention is described. \\
\hline
\end{tabular}


investigation (performance bias)

7. All relevant outcomes are

Yes

Manual blood pressure was measured measured in a standard, valid and reliable way (detection bias) using mercury sphygmomanometer four times a day. We used mean values of these data before recruitment. When the subjects met the inclusion criteria, ambulatory blood pressure was monitored using non-invasive oscillometric devices TM-2421 (A\&D Company, Japan). The recorders were programmed to start 8:00 am and measure blood pressure at 30-minute intervals for 24 hours. All participants were instructed to carry out their usual daily activities including physiotherapy.

8. The drop out rate is acceptable No At follow-up, E group lost 35\% of (attrition bias) subjects, C group lost 25\%, largely due to early discharge. There is high risk of attrition bias.

9. All the subjects are analysed in Can’t say Insufficient information available to the groups to which they were permit a judgement. randomly allocated (attrition bias) 


\section{Appendix 2 - Search strategy}

\section{Boolean phrase for Medline, CINAHL, and AMED in EBSCOHost}

((TX Berberine) OR (TX Barberry) OR (TX Chitra) OR (TX Coptis) OR (TX Daruhaldi) OR (TX Daruharidra) OR (TX Goldenseal) OR (TX Goldthread) OR (TX Huang Bai) OR (TX Huang Bo) OR (TX Huang Lian) OR (TX Huangbai) OR (TX Huanglian) OR (TX Hydrastis) OR (TX Kashmal) OR (TX Mahonia) OR (TX Oregon Grape) OR (TX Phellodendron) OR (TX Tree Turmeric)) AND ((TX Elevated Blood Pressure) OR (TX High Blood Pressure) OR (TX Htn) OR (TX Hypertension) OR (TX Hypertensive)).

Limiters - Human

\section{Boolean phrase for Embase in Ovid}

(Berberine OR Barberry OR Chitra OR Coptis OR Daruhaldi OR Daruharidra OR Goldenseal OR Goldthread OR Huang Bai OR Huang Bo OR Huang Lian OR Huangbai OR Huanglian OR Hydrastis OR Kashmal OR Mahonia OR Oregon Grape OR Phellodendron OR Tree Turmeric) AND (Elevated Blood Pressure OR High Blood Pressure OR Htn OR Hypertension OR Hypertensive).AF

Limiters - Human 